AFCRC TN-59-353

ASTIA Document No. AD 216368

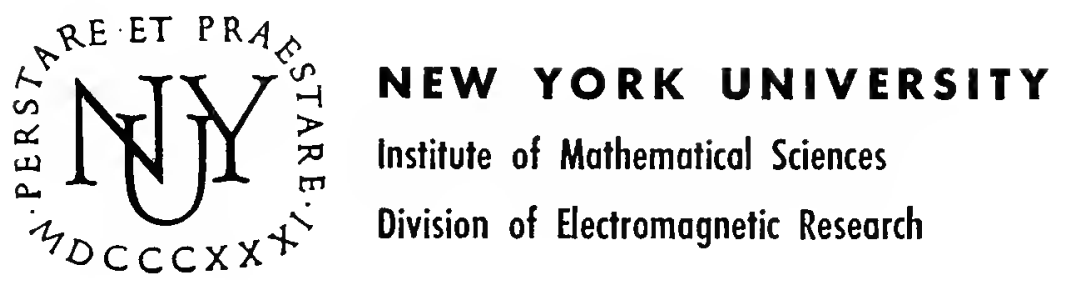

RESEARCH REPORT NO. EM-134

\title{
Alias-Free Sampling of Random Noise
}

HAROLD S. SHAPIRO and RICHARD A. SILVERMAN

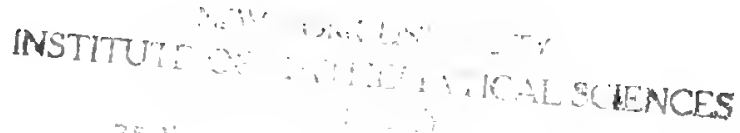

Confract No.AF $19(604) 5238$

JUNE 1959 

AFCRC-TN $-59-353$

ASTIA Document No. AD 216368

NEW YORK UNIVEPSITY

Institute of Mathematical Sciences

Division of Electromagnetic Research

RESEARCH REPORT NO. EM-134

ALIAS-FREE SAMPLING OF RAIDOM NOISE

Harold S. Shapiro and Richard A. Silverman

H Shapew

Harold S. Shapiro

Richard Q. Silverman

Richard A. Silverman

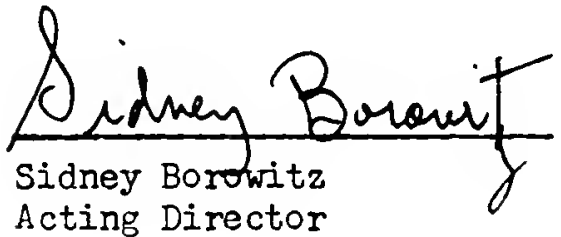

MSTIT:

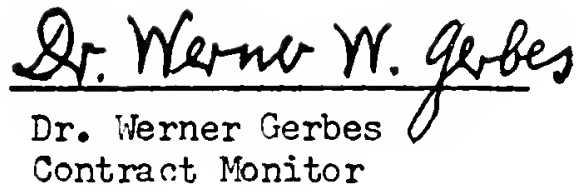

The research in this document has been sponsored by the Air Force Cambridge Research Center, Air Research and Development Command, under Contract AF .19(604)5238, and by the Office of Naval Research under Contract No. N60 ri-201(01). The publication of this report does not necessarily constitute aporoval by the Air Force of the findings or conclusions contained herein. Roproduction in whole or in part permitted for any purpose of the U.S. Govermment. 
Requests for additional copies by Agencies of the Department of Defense, their contractors, and other Government agencies should be directed to the:

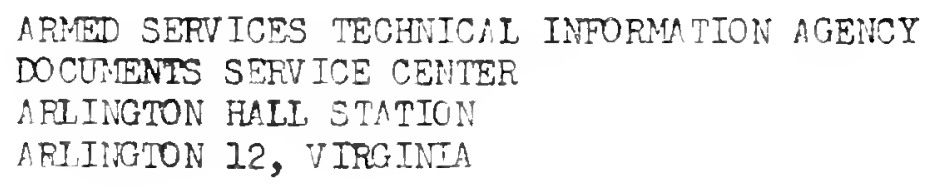

Department of Defense contractors must be established for ASTIA services or have their 'need-to-know' certified by the cognizant military agency of their projest or contract.

AlI cther persons and organizations should apply to the:

U.S. DEPARTIENT OE COMMERCE

OEFICE OF TECHNICAL SERNICES

WASH TIGTON 25, D.C. 


\section{Abstract}

We study the question of when the power spectrum of a stationary ranucm process is uniquely determined by the values of the process measured in various ways at discrete instants of time. As is well known, in the case of equi-spaced sompling, the power spectmum is not uniquely determined by the sampled data, i.e. aliasing is present. After a review of the equi-spaced case, we examine the case where the time markers are not equi-spaced, but are subject to jitter, and find that in general aliasing persists. We then consider the case where the time markers are gonerated by an additive scheme, whereby each sampling time is derived from the previous one by the addition of an independent random variable, with characteristic function $\phi(s)$. It is found that additive random sampling is alias-free if $\phi(s)$ is one-to-one on the real axis, but not aljas-free if $\phi(s)$ takes the same value at two distinct points of the open upper half-plane. Various alias-free sampling methors are exhibited, notably Poisson sampling.

\section{Tabie of Contents}

1. Introduction

2. Periodic Sampling

3. Jittered periodic sampling

L. Additive random sampling

5. Alias-free sampling methods

6. References

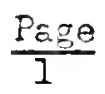

31

39 



\section{Introduction.}

A problem of great practical interest is the determination of the power spectrum $F(\omega)$ of a stationary random process $x(t)$ from measurements of $x(t)$ made at discrete instants of time. As is well known (see e.g. [l]) the usual method of sampling at equally spaced instants of time $t_{n}=n h, n=\ldots,-2,-1,0,1,2, \ldots$, does not permit unambiguous detemination of $F(\omega)$, unless $F(\omega)$ is known in advance to lie in the Nyquist band $N$, defined by $|\omega| \leq \pi / h$; otherwise, a whole class of different power spectra are compatible with the sampled values of $x(t)$. In the usual terminology, these different power spectrá are called aliases of $F(\omega)^{*}$. Thus, it is clear that if we hope to find alias-free sampling methods, i.e. methods which lead to unambiguous determination of $F(\omega)$, we must sample at unegually spaced instants of time. The case where these unequally spaced times are generated purely arithmetically seems to lead to great analytical difficulties ${ }^{*}$. However, as shown in the present paper, the case where the sampling times are chosen randomly is quite tractable. In fact, we shall see that some random sampling schemes succeed in eliminating aliasing, while others do not. In particular, the important case of Poisson sampling, where the sampling times are taken to be the occurrence times of the events of some Poisson process (e.g. the arrival times of shots in shot noise or the particle emission times in a radioactive decay process) is found to be alias-free.

\footnotetext{
*Equivalently, we call the corresponding correlation functions aliases of one another. ${ }^{* *}$ See remark on p. 219 of $[1]$.
} 


\section{Periodic Sampling.}

In what follows we shall be concerned exclusively with second order (or wide sense) properties of $x(t)$, which may therefore be taken to be a stationary Gaussian process. We assume that $x(t)$ is real, with mean zero and continuous correlation function $C(\tau)$, i.e.

$$
\operatorname{Ex}(t)=0, \operatorname{Ex}(t) x\left(t^{\prime}\right)=C\left(t-t^{\prime}\right),
$$

where $E$ denotes the expectation or ensemble average ${ }^{*}$. By the usual argument, $C(-\tau)=C(\tau)$ and $|C(\tau)| \leq c(0)$. We write the Wiener-Khintchine relations in the form

$$
C(\tau)=\int_{-\infty}^{\infty} \exp (i \omega \tau) F(\omega) d \omega, F(\omega)=\frac{1}{2 \pi} \int_{-\infty}^{\infty} \exp (-i \omega \tau) c(\tau) d \tau,
$$

where the even, non-negative function $F(\omega)$ is the power spectrum (more accurately, the power spectral density) of $x(t)$. It will be assumed that $F(\omega)$ is not only integrable, as follows from $\int_{-\infty}^{\infty} F(\omega) d \omega=\operatorname{Ex}^{2}(t)$, but also square-integrable. Symbolically ${ }^{*}$, we have $F(\omega) \in I^{I} \cap I^{2}$. It follows by Plancherel's theorem that $C(\tau) \in L^{2}$, and that the second

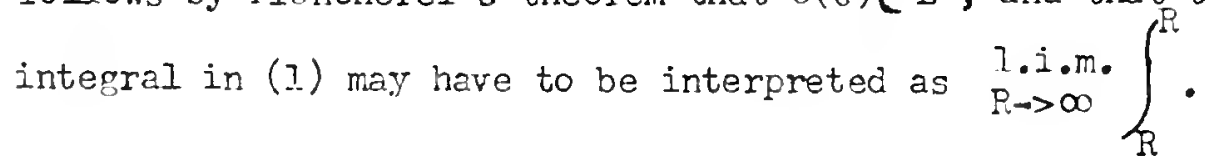

\footnotetext{
* We shall always assume that $x(t)$ has the ergodicity needed to replace the operation $E$ by suitable infinite time averages. In the case of Caussian $x(t)$, it follows by a theorem of Haruyama [2, Thr. 4] that $x(t)$ is ergodic, since the required continuity of the spectral distribution function of $x(t)$ is implicit in the representation (1). In this first study of alias-free sampling, we shall not study the variance of finite-time power spectrum estimates (as done e.g. in [1]). "By $f(\omega) \in L^{p}(a, b), p=1,2$, we mean as usual that the (Iebesgue) integral $\int_{a}^{b}|f(\omega)|^{p} d \omega$ is finite. We abbreviate $L^{p}(-\infty, \infty)$ to $I^{p}$.
} 
Suppose now that we sample $x(t)$ periodically (i.e. with equal spacing) at the points $t_{n}=n h, n=\ldots,-2,-1,0,1,2, \ldots$, where $\mathrm{h}>0$ is the sampling interval. This generates the stationary random sequence $x\left(t_{n}\right)=x(n h)$, with mean zero and correlation function (equivalently, correlation sequence)

$$
c_{h}(n)=c(n h) \quad, \quad n=\ldots,-2,-1,0,1,2, \ldots
$$

Since $C(\tau)$ is even, we have $c_{h}(-n)=c_{h}(n)$. The discrete analogs of (I), which will be needed later, are

$$
c_{h}(n)=\int_{-\pi}^{\pi} \exp (i \omega n) f_{h}(\omega) d \omega, \quad f_{h}(\omega)=\frac{1}{2 \pi} \sum_{n=-\infty}^{\infty} \exp (-i \omega n) c_{h}(n),
$$

where $f_{h}(\omega)$, the power spectrum of $x\left(t_{n}\right)$, is defined only in the interval $(-\pi, \pi)$.

We now give two different ways of constructing aliases for the case of periodic sampling. The first method relies on the fact that any two correlation functions which agree on the "lattice" of points $t_{n}=n h$ are obviously aliases with respect to periodic sampling with spacing $h$. To construct such a pair of correlation functions, let $h(\tau)$ denote any real even function in $L^{1} \cap L^{2}$, possessing a continuous second derivative and vanishing at the points $t_{n}=n h^{*}$. Then the

* We exclude the trivial case $h(\tau) \equiv 0$. 
Fourier transform

$$
H(\omega)=\frac{1}{2 \pi} \int_{-\infty}^{\infty} \exp (-i \omega \tau) h(\tau) d \tau
$$

is real, even and in $L^{I} \cap I^{2}$ (since $H(\omega)=O\left(|\omega|^{-2}\right.$ ) for large $\omega$ ). If now we write

$$
H_{+}(\omega)=H(\omega), H(\omega) \geq 0,
$$

$$
H_{+}(\omega)=0, H(\omega)<0,
$$

and

(4)

$$
H_{-}(\omega)=-H(\omega), \quad H(\omega)<0,
$$

$$
H_{-}(\omega)=0 \quad, H(\omega) \geq 0,
$$

then $H_{+}(\omega)$ and $H_{-}(\omega)$ are a pair of even, non-negative functions in $I^{1} \cap L^{2}$, whose Fourier transforms $C_{+}(\tau)$ and $C_{-}(\tau)$ agree on the lattice $t_{n}=n h$, and hence are aliases of each other." Note that $H_{+}(\omega)$ and $H_{-}(\omega)$ are not only distinct, but even non-overlapping. However, this method can also be used to construct aliases which lie in the same frequency band. We merely note that all the functions

$$
\mathrm{H}_{\mathrm{a}}(\omega)=\mathrm{aH}_{+}(\omega)+(1-2) \mathrm{H}_{-}(\omega), 0 \leq a \leq 1,
$$

are aliases of one another. In fact, more generally, any element of

\footnotetext{
*By construction, $C_{+}(\tau)$ and $C_{-}(\tau)$ are automatically positive definite, and hence correlation functions.
} 
the convex hull ${ }^{*}$ of a set of alias power spectra is another alias.

Using the same construction, we can show that knowing the correlation functions of the finite family of random sequences $x\left(n h_{1}\right), \ldots, x\left(n h_{m}\right)$ is not enough to eliminate aliases, i.e., there exist pairs of correlation functions which agree on any finite number of lattices of equally spaced points. It is merely necessary to choose the function $h(\tau)$ in the above construction to be any real even function in $I^{I} \cap L^{2}$, possessing a contimuous second derivative and vanishing on all the lattices $\mathrm{nh}_{1}, \ldots, \mathrm{nh}_{\mathrm{m}}$, and then construct $H_{+}(\omega)$ and $H_{-}(\omega)$ as before. Again, more aliases, with overlapping spectra, can be constructed by using (5).

The second method of constructing aliases is based on a detailed examination of the relation between the power spectrum $f_{h}(\omega)$ of the random sequence $x(n h)$ and the power spectrum $F(\omega)$ of the underlying process $x(t)$. Unlike the first method, it can be used to construct aliases for any given power spectrum (or, equivalently, for any given correlation function). We begin by writing (see [3], p. 57)

$$
c_{h}(n)=c(n h)=\sum_{k=-\infty}^{\infty} \int_{2 \pi k \rho}^{2 \pi(k+1) \rho} \exp (i \omega n h) F(\omega) d \omega
$$

$$
=\int_{-\pi \rho}^{\pi \rho} \exp (i \omega n h)\left\{\sum_{k=-\infty}^{\infty} F(\omega+2 \pi k \rho)\right\} d \omega,
$$

*By the convex hull of a set of functions $f_{n}, I \leq n \leq N$, is meant the set of all functions of the form $\sum_{n=1}^{N} a_{n} f_{n}, 0 \leq a_{n} \leq 1$, where $\sum_{n=1}^{N} a_{n}=1$. 
where

$$
\rho=I / h
$$

is the sampling rate. At this point, it is convenient to introduce the linear operator $\gamma \equiv \gamma_{\rho}{ }^{*}$, defined by

$$
\gamma f(\omega)=\sum_{k=-\infty}^{\infty} f(\omega+2 \pi k p)
$$

The following properties of the operator $W$ are easily verified:

1. If $f(\omega) \in \mathrm{L}^{1}$, then $\gamma(f(\omega)$ exists for almost all $\omega$ and has period $2 \pi \rho^{* * *}$.

2. If $f(\omega) \in I^{l}$, then $\mathcal{W} f(\omega) \in I^{l}(-\pi \rho, \pi \rho)$, and in fact

$$
\int_{-\pi \rho}^{\pi \rho} \gamma f(\omega) d \omega=\int_{-\infty}^{\infty} f(\omega) d \omega
$$

3. If $f(\omega)$ is contimuous and $f(\omega)=0\left(|\omega|^{-1-\varepsilon}\right), \varepsilon>0$, then $\gamma \gamma$ $f(\omega)$ is continuous ${ }^{* *}$.

4. $\gamma f(\omega+2 \pi n \rho)=\gamma(f(\omega)$, where $n$ is any integer.

5. If $h(\omega)$ has period $2 \pi \rho$, then $\gamma h(\omega) f(\omega)=h(\omega)) / f(\omega)$.

Suppose now that $f(\omega) \geq 0$, as in the case of power spectra. Then $f(\omega)$ can be regarded as a distribution of mass on the w-axis, and $f(\omega)$ is the mass distribution on the circumference of a circle of radius $\rho$

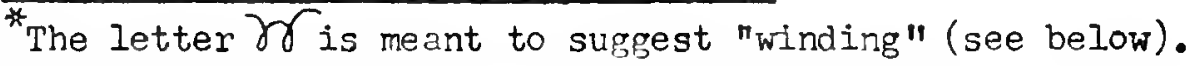
* In this connection, note that Wiener's class $M_{1}$, defined in [4], p. 73 , is essentially the class of continuous $\mathrm{I}^{1}$ functions whose "'wound-up"versions are finite (and hence continuous).
} 
which results when the w-axis is wound up on the circle in such a way that the point $\omega=0$ on the line coincides with the point $\omega=0$ on the circle; in this construction, superimposed mass simply adds. Comparing (2), (6) and (7), we see at once that the relation between the power spectrum $f_{h}(\omega)$ of the random sequence $x(n h)$ and the power spectrum $F(\omega)$ of the underlying process $x(t)$ is just $f_{h}(\omega)=\rho h_{F}(\rho \omega)$, i.e., $f_{h}(\omega)$ is the "wound-up" version of $F(\omega)$, measured in angular units. Thus, any other power spectrum $\hat{F}(\omega)$ which gives the same mass distribution when wound up on a circle of radius $\rho$ is an alias of $F(\omega)$, with respect to periodic sampling at rate $\rho$, and conversely, all aliases of $F(\omega)$ wind up to the same mass distribution. From this point of view, we can create any number of aliases of $F(\omega)$ by shifting some or all of the spectrum $F(\omega)$ through integral multiples of $2 \pi \rho$. More precisely, given any decomposition $F(\omega)=\sum_{n=1}^{\infty} F_{n}(\omega)$, where the $F_{n}(\omega)$ are all non-negative, construct the new spectrum

$$
\hat{F}(\omega)=\frac{1}{2} \sum_{n=1}^{\infty}\left\{F_{n}\left(\omega+2 \pi k_{n} \rho\right)+F_{n}\left(-\omega+2 \pi k_{n} \rho\right)\right\},
$$

where the $k_{n}$ are arbitrary integers. Then $\hat{F}(\omega)$ is even, non-negative and integrable, and moreover

$$
\begin{aligned}
\gamma \gamma F(\omega) & =\frac{1}{2} \sum_{n=1}^{\infty}\left\{\gamma \gamma_{n}\left(\omega+2 \pi k_{n} \rho\right)+\partial \gamma_{F_{n}}\left(\omega+2 \pi k_{n} \rho\right)\right\} \\
& =\frac{1}{2} \sum_{n=1}^{\infty}\left\{\partial \gamma_{F_{n}}(\omega)+\gamma \gamma_{F_{n}}(-\omega)\right\}=\frac{1}{2}\left\{\gamma \gamma_{F}(\omega)+\gamma \gamma_{F}(-\omega)\right\}=\gamma \gamma(\omega),
\end{aligned}
$$

as required. 
We note in passing that the technique developed above can also be used to construct correlation functions which vanish at all points of the sequence $t_{n}=n h, n \neq 0$. For suppose $F(\omega)$ is any power spectrum for which $/ \mathrm{F}(\omega)$ has a positive lower bound* Then the power spectrun $H(\omega)=F(\omega) / \delta / F(\omega)$ obviously satisfies $\gamma / H(\omega) \equiv 1$, whence it follows from (2) that

$$
c_{h}(n)=c(n h)=2 \pi \rho \delta_{\text {on }},
$$

where $\delta_{m n}$ is the Kronecker delta, i.a. $c(n h)=0$ for $n \neq 0$, as required.

3. Jittered periodic sampling. When trying to implement the periodic sampling seheme, we have to expect deviations of the sampling times from the values nh, due to jitter in the device generating the time markers. We now inquire as to the effect that such inaccuracy has on gliasing; in particular, it is conceivable that the jitter actually present, or some extra jitter deliberately introduced, might eliminate the aliasing encountered with ideal periodic sampling. This leads us to consider the following modification of ideal periodic sampling: Let the sampling times be of the form $t_{n}=n h+r_{n}, n=\ldots,-2,-1,0,1,2, \ldots$, where the $\gamma_{n}$ are a family of independent, identically distributed Gaussian random variables, with mean zero and varience $\sigma^{2}$, i.e. with

*In particular, this implies that $\int_{-\pi}^{\pi} \log f_{h}(\omega) d \omega>-\infty$, so that the random sequence $x\left(t_{n}\right)$ is indeterministic (see e.g. [3], p. 69). 
conmon probability density

$$
p(\tau)=\frac{1}{\sqrt{2 \pi} \sigma} \exp \left(-\tau^{2} / 2 \sigma^{2}\right)
$$

The condition for small jitter is $\sigma \ll h$; in the limit $\sigma=0, p(\tau)$ reduces to $\delta(\tau)$, the Dirac delta function, and we hove ideal periodic sampling. Note that $E t_{n}=n h$, so that the average spacing between sampling times is still $h$.

Since there is no statistical dependence between the $\gamma_{n}$ and $x(t)$, the zero-mean random sequence $x\left(t_{n}\right)$ is stationary (with respect to the product statistics of the $\gamma_{n}$ and $x(t)$ ) with correlation function ${ }^{*}$ (8)

$$
c_{h}(n)=E x\left(t_{m+n}\right) x\left(t_{m}\right)=E\left[E x\left(t_{m+n}\right) x\left(t_{m}\right) ; t_{m+n} \text { and } t_{n} \text { fixed }\right]
$$

$$
=\int_{-\infty}^{\infty} \sigma(\tau) p_{n}(\tau) d \tau,
$$

where $p_{n}(\tau)$, the probability density of $t_{m+n}-t_{m}$, is independent of $m$. For $n=0$, we have $p_{0}(\tau)=\delta(\tau)$, and $(8)$ reduces to $c_{h}(0)=c(0)$, a relation which is obvious from the fact that the mean square of any sequence sampled from $x(t)$ must be the same as the mean square of $x(t)$ itself.

\footnotetext{
* See [3], p. 58. The slight abuse of notation in (8) is transparent, $i_{0} e .$, the first $E$ is an averace over the product statistics of the $\gamma_{n}$ and $x(t)$, whereas the second $E$ is an average over the statistics of the $\gamma_{n}$ and the third $E$ over the statistics of $x(t)$.
} 
Now if $g(\tau)$ is the probability density of a Gaussian randon: variable with mean zero and variance $2 \sigma^{2}$, i.e.

$$
g(\tau)=\frac{1}{2 \sqrt{\pi} \sigma} \exp \left(-\tau^{2} \Lambda \sigma^{2}\right),
$$

we see at once that

$$
c_{h}(n)=\int_{-\infty}^{\infty} g(n h-\tau) c(\tau) d \tau, n \neq 0
$$

Since $g(n h-\tau)$ does not reduce to $\varepsilon(\tau)$ for $n=G,(20)$ is not valid for $n=0$; instead, as already noted, we have $c_{h}(0)=c(0)$. However, we shall assume that the quantity

$$
d_{h}(0)=\int_{-\infty}^{\infty} \varepsilon(\tau) c(\tau) d \tau,
$$

obtained by setting $\mathrm{n}=0$ in the right-hand side of (10), is known fron: a suitable side experiment. For example, we might sample not only at the points $t_{n}$, but also at the points $t_{n}+h$, and calculate*

$$
d_{h}(0)=\lim _{N \rightarrow \infty} \frac{1}{N} \sum_{n=I}^{N} x\left(t_{n}+h\right) x\left(t_{n+1}\right)
$$

Or we might mark off two sets of random times $t_{n}=n h+r_{n}$, $t_{n}^{\prime}=n h+r_{n}^{\prime}$, where the $r_{n}^{\prime}$ are another set of independent Gaussian

\footnotetext{
"There is perhaps a slight contradiction in (Ia), for although the times $t_{n}$ are subject to jitter, it is assumed that no additional jitter occurs in marking off the times $t_{n}+h$.
} 
random variables with common distribution (9), and calculate

$$
d_{h}(0)=\lim _{N \rightarrow \infty} \frac{I}{N} \sum_{n=1}^{N} x\left(t_{n}\right) x\left(t_{n}^{\prime}\right)
$$

(The $c_{h}(n), n \neq 0$, can be calculated from either the $t_{n}$ or the $t_{n}^{\prime}$.) Gur primary justification for assuming that $d_{h}(0)$ is known is that it is easily calculable from an ensemble point of view. In fact, indicating a "typical" infinite set of sample functions of the process $x(t)$ by $x_{i}(t), 1 \leq i<\infty$, we have

$$
a_{h}(c)=\lim _{N \rightarrow \infty} \frac{1}{N} \sum_{n=1}^{N} x_{i}\left(t_{n}\right) x_{i+1}\left(t_{n}\right)
$$

The issue involved is that the various points labelled $t_{n}$ ( $n$ fixed) are scattered in time when looked at across the ensemble. In any event, since, as we shall see below, aliasing is in general present even when $d_{h}(0)$ is known, it is present a fortiori in the absence of this extra information.

We observe next that the comolution of $c(\tau)$ with $g(\tau)$, i.e.

$$
D(\tau)=\int_{-\infty}^{\infty} g(\tau-u) c(u) d u
$$

is itself a correlation function, as follows at once from the fact that it has the non-negative Fourier transform $H(\omega)=F(\omega) G(\omega)$, where

$$
G(\omega)=\exp \left(-\sigma^{2} \omega^{2} / \varepsilon\right)
$$


Thus the sequence

$$
\begin{aligned}
& d_{h}(n)=c_{h}(n), \quad n \neq 0, \\
& d_{h}(0)=\int_{-\infty}^{\infty} g(\tau) c(\tau) d \tau,
\end{aligned}
$$

is clearly a correlation sequence. In fact, if $y(t)$ denotes a zero-mean random process with correlation function $D(\tau)$, then $d_{h}(n)$ is the correlation function of the random sequence $y(n h)$ obtained by pericdic sampling of $y(t)$ with spacing $h$. Incidentally, this gives an independent proof that the sequence $c_{h}(n)$ is a correlation sequence, since

$$
c_{h}(n)=d_{h}(n)+a \delta_{\text {on }},
$$

where

$$
a=\int_{-\infty}^{\infty} F(\omega)\{I-G(\omega)\} d \omega>0
$$

Thus, $c_{h}(n)$ is the sum of two correlation functions and therefore itself a correlation function.

The question of whether or not aliasing occurs with jittered periodic sampling can now be stated simply as follows: Are there two (or more) correlation functions which take the same value at $\tau=0$ and which when convoled with $g(\tau)$ give the same values on the lattice $\tau=\mathrm{nh}, \mathrm{n}=\ldots,-2,-1,0,1,2, \ldots\}$ or, in spectral terms, are there two (or more) power spectra which have the same total mass and which 
when multiplied by $G(\omega)$ give the same "wound-up" version on a circle of radius $\rho$ ? (Note that both statements reduce to the case of periodic sampling when $\sigma=0$. ) As we shall now show, the answer is that aliasing persists in the presence of jitter (with an exception to be discussed). We now proceed to give two ways of constricting aliases, which parallel the methods used before for constructing aliases in the case of ideal periodic sampling.

The first method consists of finding two correlation functions $D_{+}(\tau)$ and $D_{-}(\tau)^{*}$ which vanish on the lattice $\tau=n h, n=\ldots,-2,-1,0,1,2, \ldots$, and whose Fourier transforms have the same integral when divided by $G(\omega)$. Since $G(\omega) \rightarrow 0$ as $\omega \rightarrow \pm \infty$, we shell arrange for $H_{+}(\omega)$ and $H_{-}(\omega)$, the Fourier transforms of $D_{+}(\tau)$ and $D_{-}(\tau)$, to vanish outside of some finite interval. This can be achieved by choosing $D_{+}(\tau)$ and $D_{-}(\tau)$ to be entire transcendental functions of exponential type, whence it follows by a theorem of Paley and Wiener (see e.g. [5] p. 134) that $\mathrm{H}_{+}(\omega)$ and $\mathrm{H}_{-}(\omega)$ vanish outside of some finite interval.

With this in mind, define the function

$$
h_{a}(\tau)=\left(\frac{\sin \pi \tau}{\tau}\right)^{2} \sin ^{2} \pi \tau,
$$

where $a$ is an arbitrary real number and $\rho=1 / h$ is the sampling rate. Then form the linear combination

$$
h(\tau)=A h_{a}(\tau)+h_{\beta}(\tau)
$$

* The notation anticipates the nature of the construction. 
where $\alpha \neq \beta$ and $A$ is a constant to be chosen later. The function $h(\tau)$ is real, even and in $L^{I} \cap L^{2}$, and varishes at all points of the lattice $\tau=$ nh. Its Fourier transform $H(\omega)$ is therefore real, even and in $L^{2}$. Moreover, $h(\tau)$ is an entire function of exponential type with exponent $\omega_{0}=2 \pi(\rho+\max (\alpha, \beta))$. Hence, by the Paley-ifiener theorem, $H(\omega)$ vanishes for $|\omega|>\omega_{0}$, so that both $H(\omega)$ and $H(\omega) / G(\omega)$ are in $L^{I}$. We now choose the constant A so that

$$
\int_{-\infty}^{\infty} \frac{H(\omega)}{G(\omega)} d \omega=0
$$

Since the functions $h_{\alpha}(\tau)$ and $h_{\beta}(\tau)$ are linearly independent, the resulting $h(\tau)$ cannot vanish identically. Now define the non-negative functions $H_{+}(\omega)$ and $H_{-}(\omega)$ exactly as in equations (3) and $(4)$ of the preceding section, and let their Fourier transforms be $D_{+}(\tau)$ and $D_{-}(\tau)$, which are automatically correlation functions. Then $D_{+}(\tau)$ and $D_{-}(\tau)$ agree on the lattice $\tau=n h$, and moreover, by construction the corresponding correlation functions $C_{+}(\tau)$ and $C_{-}(\tau)$, defined by (13), agree for $\tau=0$. This completes the construction of aliases by the first method.

The second method of constructing aliases is based as before on the winding construction, and has the advantage that it allows one to produce aliases for any given power spectrum. Using the correlation secuence $d_{h}(n)$ we form the function

$$
\begin{aligned}
& \hat{H}(\omega)=\frac{1}{2 \pi p} \sum_{n=-\infty}^{\infty} \exp (-i \omega n h) d_{h}(n)=F(\omega) G(\omega), \omega \in N, \\
& \hat{H}(\omega)=0, \quad \omega \notin N,
\end{aligned}
$$


where $\mathrm{N}$ is the Nyquist band, defined by $|\omega| \leq \pi p$. We also have available the quantity $c_{h}(0)=\int_{-\infty}^{\infty} F(\omega)$ dw. Now evaluate the integral $I=\int_{-\pi p}^{\pi p} \frac{\hat{\mathrm{H}}(\omega)}{\mathrm{G}(\omega)} d \omega$

Ne have

$$
\begin{aligned}
I & =\int_{-\pi \rho}^{\pi \rho} \frac{I}{G(\omega)}\left\{\sum_{n=-\infty}^{\infty} F(\omega+2 \pi \rho n) G(\omega+2 \pi \rho n)\right\} d \omega \\
& \leq \int_{-\pi \rho}^{\pi \rho}\left\{\sum_{n=-\infty}^{\infty} F(\omega+2 \pi \rho n)\right\} d \omega=\int_{-\infty}^{\infty} F(\omega) d \omega=c_{h}(0),
\end{aligned}
$$

where the equality holds if and only if $F(\omega)$ lies entirely in $N$ (i.e. vanishes almost everywhere outside of $N$ ). Thus, if the values of $I$ and $c_{h}(0)$ are equal, we know that $F(\omega)$ lies in $N$; consequently, $\Gamma(\omega)=\hat{B}(\omega) / G(\omega)$ and we can determine $F(\omega)$ uniquely in this case. Moreover, unlike the case of ideal (i.e. jitter-free) periodic sampling, we can ascertain whether or not $F(\omega)$ lies in $N$ by a simple test, namely comparison of $I$ and $c_{h}(0)$, instead of having to know a priori that $\mathrm{F}(\omega)$ lies in $\mathrm{N}$.

If $F(\omega)$ does not lie in $N$, then $I<c_{h}(0)$, and aliases of $F(\omega)$ can be constructed as follows. Define the "virtual spectrum"

$$
\begin{array}{lll}
\hat{\mathrm{F}}(\omega)=\hat{H}(\omega) / G(\omega), & & \omega \in N, \\
\hat{\mathrm{F}}(\omega)=0, & , \quad \omega \notin N ;
\end{array}
$$


$\hat{F}(\omega)=F(\omega)$ if and only if $F(\omega)$ lies in $N$. Now write $\hat{F}(\omega)$ in any way ${ }^{*}$ as the sum of two non-negative functions $\hat{F}_{1}(\omega)$ and $\hat{F}_{2}(\omega)$, and define

$$
\begin{aligned}
F_{n, a}(\omega)= & \frac{1}{2}\left\{\hat{F}_{1}(\omega)+\hat{F}_{1}(-\omega)\right\}+\frac{1-a}{2}\left\{\hat{F}_{2}(\omega)+\hat{F}_{2}(-\omega)\right\} \\
& +\frac{a}{2 G(\omega)}\left\{\hat{F}_{2}(\omega+2 \pi \rho n) G(\omega+2 \pi \rho n)+\hat{F}_{2}(-\omega+2 \pi \rho n) G(-\omega+2 \pi \rho n)\right\},
\end{aligned}
$$

where $0 \leq a \leq 1$ and $n$ is arbitrary. (Note that $F_{n, 0}(\omega)=\hat{F}(\omega)$.) Then $F_{n, a}(\omega)$ is even and non-negative, and moreover

$$
W F_{n, a}(\omega) G(\omega)=W_{F}(\omega) G_{(}(\omega)=\hat{H}(\omega) \text {. }
$$

Since $F_{2}(\omega)$ vanishes for $\omega \notin N$, it is easily seen that if $n \neq 0$

$$
\begin{aligned}
\int_{\infty}^{\infty} \frac{1}{G(\omega)}\left\{\hat{F}_{2}(\omega+2 \pi \rho n) G(\omega+2 \pi \rho n)+\hat{F}_{2}(-\omega+2 \pi \rho n) G(-\omega+2 \pi \rho n)\right\} d \omega \\
\quad>\int_{-\infty}^{\infty}\left\{\hat{F}_{2}(\omega)+\hat{F}_{2}(-\omega)\right\} d \omega,
\end{aligned}
$$

i.e., the distribution $F_{n, a}(\omega)$ has more mass than the inflial distribution $\hat{F}(\omega)$ if $0<\alpha \leq 1$. In fact, since the first integral increases with $n$, there exists an integer $n_{0}>0$ such that

$$
\int_{-\infty}^{\infty} F_{n, I}(\omega) d \omega>\int_{-\infty}^{\infty} F(\omega) d \omega
$$

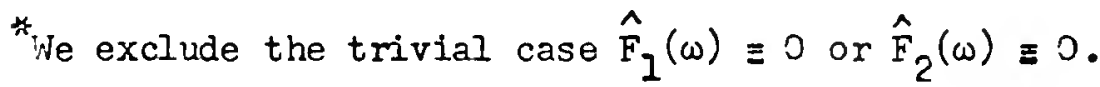


for all $|n| \geq n_{0}$. Therefore, since

$$
\int_{-\infty}^{\infty} F_{n, 0}(\omega) d \omega=\int_{-\infty}^{\infty} F(\omega) d \omega<\int_{-\infty}^{\infty} F(\omega) d \omega,
$$

and since $F_{n, a}(\omega)$ depends continuously on the parameter $a$, there is a value of $a$, say $a_{n}$, between 0 and 1 , such that

$$
\int_{-\infty}^{\infty} F_{n, a_{n}}(\omega) d \omega=\int_{-\infty}^{\infty} F(\omega) d \omega
$$

It is clear that any such function $F_{n, a}(\omega)$ is an alias of $F(\omega)$ with respect to jittered periodic sampling. This completes the construction of aliases by the second method."

4. Additive random sampling.

The reason that aliasing is still present with jittered periodic sampling seems to be that the sampling times $t_{n}$ are still "attracted" to the equi-spaced values nh. What seems to be needed to break up this regularity is some sort of "florting point" sampling scheme. Thus, we consider next additive random sampling, in which each sampling time is derived from the preceding one by the addition of an independent random variable $e^{* *}$. Specifically, let $t_{n}=t_{n-1}+\gamma_{n}$, where the $r_{n}, n=\ldots,-2,-1,0,1,2, \ldots$, are a family of icentically distributed,

* The considerations of this section can be extended to the case where $g(\tau)$ instead of being Gaussian is a function whose Fourier transform has isolated zeros only, e.g. when $g(\tau)$ vanishes outside of a finite interval. Again it is found that aliasing persists. It is also clear how to extend the second method of constructing aliases to give aliases of a more general type.

* With jittered periodic sampling, the differences between successive sampling times are not independent random variables, and the variance of $t_{n}$ is $2 \sigma^{2}$ for all $n$. On the other hand, with additive random sampling, the variance of $t_{n}$ goes to $\infty$ with $n$, if sampling starts in the finite

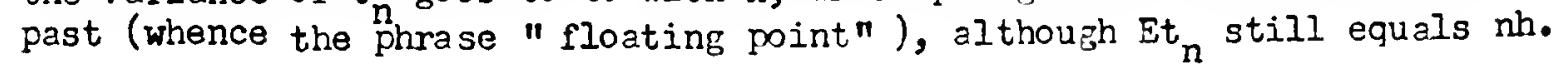


Independent random variables, with $E Y_{n}=h<\infty$ and common probability density $F(\tau)$. Of course, $p(\tau) \geq 0$ and $\int_{-\infty}^{\infty} p(\tau) d \tau=1$. We assume that $p(\tau)$ is also in $I^{2}$ and that $p(\tau)=0$ for $\tau<0$. The last condition corresponds to the reasonable reouirement that a sample time with a given index should come after all sample times with smaller indices. For later use, we introduce the Fourier transform

$$
\text { (14) } \phi(\omega)=\int_{-\infty}^{\infty} \exp (i \omega \tau) p(\tau) \mathrm{d} \tau=\int_{0}^{\infty} \exp (i \omega \tau) p(\tau) \mathrm{d} \tau,
$$

the characteristic function (in the sense of probability theory) of the distribution $p(\tau)$. The function $\phi(\omega)$ is uniformly continuous on the whole real line and satisfies the conditions

$$
\phi(0)=1,|\phi(\omega)| \leq 1, \phi(-\omega)=\varnothing(\omega), \lim _{\omega \rightarrow \pm \infty} \phi(\omega)=0,
$$

where the overbar denotes the complex conjugate. It will be important to extend (IL) to complex arguments by writing

$$
\phi(s)=\int_{0}^{\infty} \exp (\text { is } \tau) p(\tau) \mathrm{d} \tau,
$$

where $s=\omega+i \omega^{\prime}$. Eq.(15) defines a function which is analytic and bounded in the open half-plane Im $s>0$, and continuous in the closed half-plane Im $s \geq 0$. Moreover, for $\operatorname{Ims} \geq 0$, we have $|\ell(s)| \leq 1$, with equality holding only for $s=0$.

As in the case of jittered random sampling, the correlation function 
of the random sequence $x\left(t_{n}\right)$ is given by

$$
\begin{aligned}
c_{h}(n) & =E_{x}\left(t_{m+n}\right) x\left(t_{m}\right)=E\left[E x\left(t_{m+n}\right) x\left(t_{m}\right) ; t_{m+n} \text { and } t_{n} \text { fixed }\right] \\
& =\int_{-\infty}^{\infty} c(\tau) p_{n}(\tau) d \tau,
\end{aligned}
$$

where now, in view of the new definition of $t_{n}$, the probsbility density $p_{n}(\tau)$ is given by

$$
\begin{aligned}
& p_{n}(\tau)=\int_{-\infty}^{\infty} p_{n-1}(\tau-u) p(u) d u=\int_{0}^{\tau} p_{n-1}(\tau-u) p(u) d u, n \geq 2, \\
& p_{1}(\tau) \equiv p(\tau),
\end{aligned}
$$

i.e., $p_{n}(\tau), n \geq 2$, is obtained by successively convolving $p(\tau)$ with itself $n$ times. As before, $p_{0}(\tau)=\delta(\tau)$ and $c_{h}(-n)=c_{h}(n)$. Note that $p_{n}(\tau), n \geq 1$, vanishes for negative $\tau$, so that ( 8 ) becomes (17)

$$
\begin{aligned}
& c_{h}(n)=\int_{0}^{\infty} c(\tau) p_{n}(\tau) d \tau, \quad n \geq 1, \\
& c_{h}(0)=c(0) .
\end{aligned}
$$

Moreover, using Parseval's theorem, we have

$$
\int_{0}^{\infty} p_{n}^{2}(\tau) d \tau=\int_{-\infty}^{\infty}|\phi(\omega)|^{2 n} d \omega \leq \int_{-\infty}^{\infty}|\phi(\omega)|^{2} d \omega=\int_{0}^{\infty} p^{2}(\tau) d \tau,
$$

so that $p_{n}(\tau), n \geq 1$, is in the class $I^{2}$. Again applying Parseval's theorem and the convolution theorem for Fourier transforms, we find 
that the spectral equivalent of (17) is

$$
c_{h}(n)=\int_{-\infty}^{\infty} F(\omega) \phi^{n}(\omega) d \omega, n \geq 0 .
$$

The reality of $c_{h}(n)$, as defined by (18), follows from $F(-\omega)=F(\omega)$ and $\phi(-\omega)=\overline{\phi(\omega)}$.

Equations (17) and (18) exhibit a direct relation between the correlation sequence $c_{h}(n)$ and the correlation function $c(\tau)$ or power spectrum $F(\omega)$, and we shall use these formulas, particularly (18), to study aliasing in the case of additive random sampling. It is of some interest, however, to examine the relation between the spectrum $F(\omega)$ and the spectrum $f_{h}(\omega)$ of the random sequence $x\left(t_{n}\right)$. To do this, we use (2) and (18) to write *

$$
f_{h}(\omega)=\frac{1}{2 \pi} \sum_{n=-\infty}^{\infty} \exp (-i \omega n) c_{h}(n)=\frac{1}{2 \pi} \int_{-\infty}^{\infty} F(u)\left\{1+\sum_{n=1}^{\infty} \phi^{n}(u)\left(e^{i \omega n}+e^{-i \omega n}\right)\right\} d u,
$$

where the second series is convergent for all $u \neq 0$. Carrying out the sumation and using the fact that $F(\omega)$ is even, we obtain

$$
\begin{aligned}
f_{h}(\omega) & =\frac{1}{2 \pi} \int_{-\infty}^{\infty} F(u) \operatorname{Re}\left\{\frac{1+e^{i \omega} \not(u)}{1-e^{i \omega} \phi(u)}\right\} d u \\
& =\frac{1}{2 \pi} \int_{-\infty}^{\infty} F(u)\left\{\frac{1-|\phi(u)|^{2}}{\mid 1-e^{\left.i \omega_{\phi}(u)\right|^{2}}}\right\} d u,
\end{aligned}
$$

so that $f_{h}(\omega)$ exists and is non-negative everywhere in $(-\pi, \pi)$, except pernaps at $\omega=0$, where (19) becomes indeterminate. Incidentally, this 
sives an independent proof of the fact that $c_{h}(n)$ is a correlation sequence, i.e. that the sequence $x\left(t_{n}\right)$ is staticnary. Finally, we have

$$
\begin{aligned}
\int_{-\pi}^{\pi} f_{h}(\omega) d \omega & =\frac{1}{2 \pi} \int_{-\infty}^{\infty} F(u)\left\{\int_{-\pi}^{\pi} \operatorname{Re}\left\{\frac{1+e^{i \omega \phi(u)}}{1-e^{i \omega \phi(u)}}\right\} d \omega\right\} d u \\
& =\frac{1}{2 \pi} \int_{-\infty}^{\infty} F(u)\left\{\pi e \int_{|z|=1} \frac{1+z \phi(u)}{1-z \not d(u)} \frac{d z}{i z}\right\} d u=\int_{-\infty}^{\infty} F(\omega) d \omega,
\end{aligned}
$$

as is to be expected.

The question of whether aliasing occurs with additive random sampling can now be simply stated as follows: For which $p(\tau)$ is there only one correlation function which leads via (18) to a given correlation sequence $c_{h}(n)$ ? Or in spectral terms, for which $p(\tau)$ is there only one power spectrum which leads via (19) to $c_{h}(n)$ ? We now prove a theorem which gives a partial answer to this question, i.e. which gives a sufficient condition for additive random sampling to be alias-free.

Theorem 1. Additive random sampling is alias-free if the characteristic function $\phi(\omega)$ takes no value more than once on the real axis.

Proof. If aliasing is possible, then (18) is satisfied for two distinct real (non-nerative) functions in $L^{1} \cap L^{2}$, i.e., there exists a real function $H(\omega)$ in $I^{2} \cap I^{2}$, which is not a mull function ${ }^{*}$, such that

(20)

$$
\int_{-\infty}^{\infty} H(\omega) \phi^{n}(\omega) d \omega=0
$$

\footnotetext{
* By a mal function is meant a function which vanishes except on a set of measure zero.
} 
for $n \geq 0$. Thus, we must show that if $\not(\omega)$ is one-to-one on the real axis, then any $H(\omega)$ satisfying (20) must be a null function.

We begin by showing that if $\phi(\omega)$ is one-to-one on the real axis, then $\phi(\omega)$ is actua] Iy one-to-one for Ims $\geq 0$, or, in the terminology of conformal mapping, $0(s)$ is schlicht in the closed upper half plane. To see this, we note first that it follows by a Phragmen-Iindelöf theorem (see [6], p. 179) that the boundedness of $\phi(\omega)$ topether with $\phi(\omega) \rightarrow 0$ as $\omega \rightarrow \pm \infty$ implies that $\phi(s) \rightarrow 0$ uniformiy in the upper half-plane, i.e. that $\phi(s)$ can be made as small as we please outside a suitably large semicircle $\Gamma_{1}$ erected on some diameter $(-P, R)$. Let $\Gamma$ be the closed contour consisting of $\Gamma_{I}$ and the segment $(-R, P)$. Now if $a \neq 0$ is a value taken by $\phi(s)$ at some point in Ims $>0$, choose $R$ large enough so that $|\phi(s)|<\alpha$ on $\Gamma_{I}$. By the argument principle (see [6], p. 116), if $\phi(s)$ takes the value a more than once for Ims $>0$, then the image of the contour $\Gamma$ under the mapping $z=\varnothing(s)$ would have to wind more than once around the point $a$. However, this is impossible, since by hypothesis the image of the segment $(-R, R)$ of the real axis cannot intersect itself, whereas the image of $\Gamma_{I}$ is confined to a circle of radius less than $c$. Moreover, if $\not(s)$ takes the value a at some point $s_{0}$ of Ims $>0$, it cannot take the same value at a point $\omega_{0}$ of the real axis, for since $\phi(s)$ takes all values sufficiently close to $a$ in a neighborhood of $s_{0}$ (see [7], p. 184 ), and since $\phi(s)$ is continuous at $\omega_{0}$, we could then find two non-zero values near a taken twice in the open upper half-plane, which is impossible, as we have just seen. It follows that $\phi(s)$ can take no non-zero value more than once in Ims $\geq 0$. 
Moreover, $\phi(s)$ cannot vanish for Ims $>0$, for if $\phi\left(s_{0}\right)=0, I_{m} s_{0}>0$, then in a neighborhood of $s_{0}$ which lies entirely in the open upper half-plane $\phi(s)$ takes all sufficiently small values. But since $\phi(s) \rightarrow 0$ as $s \rightarrow \infty$, we could then find a small non-zero value taken twice in the open upper half-plane, which is impossible, as already noted. Moreover, $\phi(\omega)$ cannot vanish for real $\omega$, since then $\phi(-\omega)$ also vanishes, which violates the hypothesis of the theorem (recall that $\varnothing(0) \neq 0$.) Thus, we have finally shown that $\phi(s)$ is schlicht in the closed upper half plane.

We now turn to the core of the proof. Consider the analytic function $z=\phi(s)$, which maps the half-plane Ims $>0$ onto a domain $\Omega_{z}$ in the z-plane which is entirely contained in the circle $|z|=1$ and whose boundary does not intersect itself and passes through the points $z=0$ and $z=1$. Next consider the analytic function

$$
\zeta=\xi(s)=\frac{1}{s-B+i},
$$

where $\beta$ is a real constant; $\xi(s)$ maps the half-plane Ims $\geq 0$ onto a circle $\Omega_{\zeta}$ in the $\zeta$-plane which has $\zeta=0$ on its boundary. Now

$$
\zeta=\xi(s)=\xi\left(\phi^{-1}(z)\right) \equiv J(z)
$$

is a single-valued function, analytic in the domain $\Omega_{z}$ and continuous on the boundary of $\Omega_{z}$, which maps $\Omega_{z}$ onto $\Omega_{\zeta}$ in such a way that the points $z=0$ and $\zeta=0$ coincide. By a theorem of walsh (see $[8]$, p. 36), given any $\varepsilon>0$, there is a polynomial $P(z)=c_{0}+c_{1} z+\ldots+c_{n} z^{n}$

$\phi_{\text {By }} \phi^{-1}(z)$ we mean the inverse function of $\phi(z)$. 
such that

$$
|J(z)-P(z)|<\varepsilon
$$

on the boundery $B_{z}$ of $\Omega_{z}$. Since $J(0)=0$, we have $|P(0)|<\varepsilon$. Thus, setting $P_{I}(z)=P(z)-c_{0}$, so that $P_{I}(0)=0$, we have

$$
\left|J(z)-P_{I}(z)\right|<2 \varepsilon
$$

on $\mathrm{B}_{2}$. It follows that

$$
\left|\xi(\omega)-P_{1}(\phi(\omega))\right|<2 \varepsilon,
$$

since $\varnothing(s)$ maps the real axis into $B_{2}$.

Suppose now that $H(\omega)$ satisfies (20) for $n \geq 1$. Then, using (20) and (21), we have

$$
\left|\int_{-\infty}^{\infty} \frac{H(\omega)}{\omega-\beta+i} d \omega\right|=\left|\int_{-\infty}^{\infty} H(\omega)\left\{\xi(\omega)-F_{I}(\phi(\omega))\right\} d \omega\right|<2 \varepsilon \int_{-\infty}^{\infty}|H(\omega)| d \omega .
$$

Since $H(\omega) \in L^{l}$ and $\varepsilon$ is arbitrary, it follows that

$$
\int_{-\infty}^{\infty} \frac{H(\omega)}{\omega-\beta+i} d \omega=0
$$

Taking the imeginary part of (22), we obtain

$$
\int_{-\infty}^{\infty} \frac{H(\omega)}{1+(\omega-\beta)^{2}} d \omega=0 \text {, }
$$

since $H(\omega)$ is real. Recalling that $\beta$ is an arbitrary real number, we see that the convolution of $\mathrm{H}(\omega)$ and $1 /\left(1+\omega^{2}\right)$ vanishes identically. It follows from the convolution theorem for Fourier transforms that 
$h(\tau) \exp (-|\tau|)$ is a null function, where $h(\tau)$ is the Fourier transform of $H(\omega)$. But since $\exp (-|\tau|)$ does not vanish for finite $\tau, h(\tau)$ itself and finally $\mathrm{H}(\omega)$ is a mull function, i.e. aliasing is impossible. (Note that because of the special nature of the mapping $J(z)$, we have not used (20) for the value $n=0$, so that knowledge of the number $c_{h}(0)$ is superfluous.) This completes the proof of Theorem 1 .

Next we prove a conditional converse of Theorem 1 .

Theorem 2. If the characteristic function $\phi(s)$ takes the same value at two different points of the open upper half-plane, then aliasing occurs with additive random sampling.

Proof. We have $\phi\left(s_{1}\right)=\varnothing\left(s_{2}\right)$, where $s_{1} \neq s_{2}$ and Ims $>0, I_{1} s_{2}>0$. It is asserted that there exists a non-null real even function in $I^{1} \cap I^{2}$ such that $(20)$ is valid for $n \geq 0$. Equivalently, ${ }^{*}$ if $h(\tau)$ is the Fourier transform of $H(\omega)$ and $A$ is the class of Fourier transforms of $I^{I}$ functions, it is asserted that there exists a non-null real even function $h(\tau)$ in $A \cap I^{2}$, with $h(0)=\int_{-\infty}^{\infty} H(\omega) d \omega=0$, such that

$$
\int_{-\infty}^{\infty} h(\tau) p_{n}(\tau) d \tau=\int_{0}^{\infty} h(\tau) p_{n}(\tau) d \tau=0, n \geq I,
$$

where the $p_{n}(\tau)$ are given by (16). We shall show that the assumption that there are no such $H(\omega)$ and $h(\tau)$ leads to a contradiction, thereby proving the theorem.

Suppose there is no $h(\tau)$ with the specified properties which

\footnotetext{
* Fecall that Fourier transformation is a unitary transformation of $L^{2}$ onto itself (see [4], p. 70).
} 
satisfies (23). Then since the class $\mathcal{H}$ of such $h(\tau)$ is dense * in the real function space $L^{2}(0, \infty)$, it follows that there is no non-null function in $L^{2}(0, \infty)$ for which (23) is satisfied, and consequently that any function in $\mathrm{L}^{2}(0, \infty)$ can be approximated in $I^{2}$-norm by linear combinations of the $p_{n}(\tau), n \geq I$ (see $[4], p .37$ ). Equivalently (see footnote, p. 25), the Fourier transform of any function in $L^{2}(0, \infty)$ can be approximated in $L^{2}-$ norm by linear combinations of the powers $\phi^{\mathrm{n}}(\omega), \mathrm{n} \geq 1$. We choose this function in $I^{2}(0, \infty)$ to be $\exp (-\tau)$, with Fourier transform $I /(I-i \omega)$; this choice is motivated by the fact triat $I /(1$ - is ) is a schlicht function. Then we have

(24) $\lim _{n \rightarrow \infty} \int_{-\infty}^{\infty}\left|P_{n}(\phi(\omega))-\frac{1}{1-i \omega}\right|^{2} d \omega=0$, where

$$
P_{n}(x)=a_{n 1} x+a_{n 2} x^{2}+\ldots+a_{n n} x^{n}
$$

is a suitable polynomial with real coefficients.

Now form the integral

$$
\frac{1}{2 \pi} \int_{\Gamma} \frac{1}{s-s_{0}}\left\{P_{n}(\phi(s))-\frac{1}{1-i s}\right\} d s,
$$

\footnotetext{
*To see this, note that the class of step-functions is dense in $I^{2}(0, \infty)$ (see [4], p. 24) and that each step can be approximated by a "trapezoidal function" ; in particular, a step at the origin can be approximated by a trapezoidal function vanishing at the origin. Since every trapezoidal function is in $A \cap I^{2}$ (see [4], p. 89), a subset of 4 is dense in $\mathrm{L}^{2}(0, \infty)$. (Here, and below, we depart from our usual notation and use $\mathrm{I}^{2}(0, \infty)$ to denote the space of real functions $h(\tau)$ for which $\int_{0}^{\infty} h^{2}(\tau) d \tau<. \infty$.)
} 
where Im $s_{0}>0^{\circ}$ and $\Gamma$ is a contour like the one used in Theorem 1 , i.e. a large semicircle $\Gamma_{I}$ erected on the segment $(-R, R)$ as diameter. By Cauchy's theorem, the integral (25) is just the expression in curly brackets evaluated at $s=s_{0}$. Furthermore, it is easy to see that the contribution to $(25)$ coming from $\Gamma_{1}$, the semi-circular part of the contour $\Gamma$, goes to zero as $R \rightarrow \infty$. $^{*}$ Combining these facts and using the Schwarz inequality, we have

$$
\begin{aligned}
& \left|P_{n}\left(\phi\left(s_{0}\right)\right)-\frac{1}{1-i s_{0}}\right|=\left|\frac{1}{2 \pi i} \int_{-\infty}^{\infty} \frac{1}{\omega-s_{0}}\left\{P_{n}(\phi(\omega))-\frac{1}{1-i \omega}\right\} d \omega\right| \\
& \leq \frac{1}{2 \pi}\left\{\int_{-\infty}^{\infty} \frac{d \omega}{\left|\omega-s_{0}\right|^{2}}\right\}^{\frac{1}{2}}\left\{\int_{-\infty}^{\infty}\left|P_{n}(\phi(\omega))-\frac{1}{1-i \omega}\right|^{2} d \omega\right\}^{\frac{1}{2}} \\
& =k\left\{\int_{-\infty}^{\infty}\left|P_{n}(\phi(\omega))-\frac{1}{1-i \omega}\right|^{2} d \omega\right\}^{\frac{1}{2}},
\end{aligned}
$$

where $k$ can be chosen so that the inequality holds uniformly for so in any closed bounded subset of the open half-plane Ims $>0$. Choose this subset to contain the points $s_{1}$ and $s_{2}$ for which $\phi\left(s_{1}\right)=\phi\left(s_{2}\right)$. Then by (24), if $\mathrm{n}$ is large enough, we have both

and

$$
\left|P_{n}\left(\phi\left(s_{1}\right)\right)-\frac{1}{1-i s_{1}}\right|<k \varepsilon
$$

$$
\left|P_{n}\left(\phi\left(s_{2}\right)\right)-\frac{1}{1-i s_{2}}\right|<k \varepsilon \text {. }
$$

whence

$$
\left|\frac{1}{1-i s_{1}}-\frac{1}{1-i s_{2}}\right|<2 k \varepsilon \text {, }
$$

As already shown, as $s \rightarrow \infty, \phi(s) \rightarrow 0$ uniformly in the upper half-plane. 
or, since $\varepsilon$ is arbitrary

$$
\frac{1}{1-i s_{1}}=\frac{1}{1-i s_{2}}
$$

However, (27) is impossible for $s_{1} \neq s_{2}$. This contrediction establishes the existence of a real even $H(\omega)$ in $I^{I} \cap I^{2}$ satisfying (20) for $n \geq 0$. The construction of aliases now proceeds in the usual way, $i_{. e}$. we introduce the functions $H_{+}(\omega)$ and $H_{-}(\omega)$ defined by (3) and (4). Then $H_{+}(\omega)$ and $H_{-}(\omega)$, and more generally the functions $H_{a}(\omega)$ defined by $(5)$, are a set of elias power spectra. This completes the proof of Theorem 2.

From an abstract point of view, the question of whether or not aliasing is present with a given method of sampling is just the question of whether or not the mapping from a space whose elements are zero-mean Gaussian random processes to another space whose elements are zero-mean Gaussian random sequences is a one-to-one mapping. Thus, the fact that in the case of additive random sampling, a decisive role is played by the question of whether or not the mapping

$$
z=\phi(s)=\int_{0}^{\infty} \exp (\text { is } \tau) p(\tau) d \tau
$$

is one-to-one is, at least retrospectively, not too startling.

The method for explicitly reconstructing the correlation function $c(\tau)$ of the underlying sampled process $x(t)$, in a case where aliasing 
is absent (as revealed by Theorem 1) is straightforward. First we note that the functions $\phi^{n}(\omega), n \geq 1$, and correspondingly the functions $p_{n}(\tau), n \geq 1$, are linearly independent; for if a linear combination of the $\phi^{\mathrm{n}}(\omega)$ with non-zero coefficients vanishes identically, e.g. $a_{n 1} \phi(\omega)+a_{n 2} \phi^{2}(\omega)+\ldots+a_{n n} \phi^{n}(\omega) \equiv 0$ then, since $\phi(\omega)$ is continuous, factoring this polynomial leads to the contradictory conclusion that $\phi(\omega) \equiv$ const. Next, we apply the orthogonalization procedure to the functions $p_{n}(\tau), n \geq 1$, obtaining the orthonormal set $q_{n}(\tau), n \geq 1$, which obey the relations

$$
\int_{0}^{\infty} g_{m}(\tau) g_{n}(\tau) d \tau=\delta_{m n}
$$

We then express the $q_{n}(\tau)$ in the usual fashion (see e.g. [g], p.22) in terms of linear combinations of the $p_{n}(\tau)$, i.e.

$$
q_{n}(\tau)=b_{n 1} p_{1}(\tau)+b_{n 2} p_{2}(\tau)+\ldots+b_{n n} p_{n}(\tau), n \geq 1
$$

Phltiplying (28) by $C(\tau)$ and integrating from 0 to $\infty$, we obtain the formula

$$
R_{n}=\int_{0}^{\infty} q_{n}(\tau) \tau(\tau) d \tau=b_{n l} c_{h}(1)+b_{n 2} c_{h}(2)+\ldots+b_{n n} c_{h}(n), n \geq 1,
$$

relating the generalized Fourier coefficients $\beta_{n}$ to the correlation sequence $c_{h}(n)$. Finally, in terms of the $\beta_{n}$ and the $q_{n}(\tau)$, we have

$$
C(\tau)=\sum_{n=1}^{\infty} \beta_{n} q_{n}(\tau), \quad \tau \geq 0,
$$

where the expansion is valid in the sense of mean convergence (i.e. 
convergence in the $\mathrm{L}^{2}$-norm). Equivalently, we can develop an expression analogous to $(30)$ for $F(\omega)$, the power spectrum of $x(t)$. Recalling that $c(-\tau)=c(\tau)$ and taking the Fourier transform of $(30)$, we have

$$
F(\omega)=\frac{1}{2 \pi} \int_{-\infty}^{\infty} c(\tau) \exp (-i \omega \tau) d \tau=\frac{1}{2 \pi} \sum_{n=1}^{\infty} \int_{0}^{\infty} c(\tau)\{\exp (i \omega \tau)+\exp (-i \omega \tau)\} d \tau
$$

$$
=\frac{1}{2 \pi} \sum_{n=1}^{\infty} \beta_{n}\left\{\Psi_{n}(1)+\Psi_{n}(-\omega)\right\} \quad,
$$

where

(32) $\Psi_{n}(\omega)=\int_{0}^{\infty} g(\tau) \exp (i \omega \tau) d \tau=b_{n 1} \not(\omega)+b_{n 2^{\phi}} \phi^{2}(\omega)+\ldots+b_{n n} \phi^{n}(\omega), n>1$ and the coefficients $\beta_{\mathrm{n}}$ and $b_{\mathrm{rm}}$ are the same as in (28) and (29). Since $\phi(-\omega)=\overline{\varnothing(\omega)}$, we have $\Psi_{n}(-\omega)=\bar{\Psi}_{n}(\omega)$, so that the even function defined by the last term of (3I) is real, as required. Again the expansion (31) is valid in the sense of mean convergence. (Actually, the validity of $(30)$ and $(31)$ in the sense cf mean convergence requires the completeness of the functions $p_{n}(\tau), n \geq 1$, in $L^{2}(c, \infty)$. This does not quite follow from our proof of Theorem 1, since there we showed that (20) implies that $\mathrm{H}(\omega)$ is a null-function with the aid of the assymption that $H(\omega)$ is in $I^{1}$ as well as in $L^{2}$. By a more inrolved argument, one can establish the required completeness of the $p_{n}(\tau)$ in $I^{2}(0, \infty)$, i.e. one can drop the hypothesis $H(\omega) \in I^{1}$. (See [10]).

\footnotetext{
* Since $C(\tau)$ is continuous by assumption and in practice will generally have further regularity properties, we can expect that the expansion (30) will usually be corvergent, or at least sumable by arithmetic means. Then, since the number $c_{h}(0)$ has not been used in forming (30), we can check $(30)$ by calculating $c(0)$ and seeing whether $c_{h}(0)=c(c)$ holds. We can also expect that (3I) will usually be convergent or surmable.
} 


\section{Alias-free sampling methods.}

Using the theory of the preceding section, we now exhibit a number of examples of additive random sampling methods, scme of which are alias-free and some of which are not. Consider first "Poisson sampling" corresponding to the choice

$$
p(\tau)=\rho \exp (-\rho \tau), \quad \tau \geq 0,
$$

$$
p(\tau)=0 \quad, \quad \tau<0
$$

which by (16) Ieads to

(34)

$$
p_{n}(\tau)=\frac{p^{n} \tau^{n-1}}{(n-1)} \exp (-\rho \tau), \tau \geq 0,
$$

$$
p_{n}(\tau)=0, \quad \tau<0
$$

for $\mathrm{n} \geq 1$; with the choice (33) the sampling times are the occurrence times of the events in a Poisson process with average rate $p$. Since the corresponding characteristic function

$$
\phi(s)=\frac{\rho}{\rho-i s}
$$

takes no value more than once on the real axis (or anywhere in the complex plane), it follows by Theorem I that Poisson sampling is alias-free.*

Reconstruction of the correlation function $c(\tau)$ of the sampled process $x(t)$ from the correlation sequence $c_{h}(n)$ is particularly

\footnotetext{
* That Poisson sampling is alias-free also follows from known proofs of the completeness of the Laguerre functions without recourse to Theorem 1 .
} 
simple in this case, as might be expected from the fact that the familiar Laguerre functions are obtained by orthogonalizing the functions $\exp (-\tau / 2), \tau \exp (-\tau / 2), \tau^{2} \exp (-\tau / 2), \ldots$, which differ only trivially from (34). First we recall the definition of the Laguerre polynomials (see [9], p. 97)

(35) $\quad I_{n}(\tau)=\frac{e^{\tau}}{n !} \frac{d^{n}}{d \tau^{n}}\left(\tau^{n} e^{-\tau}\right)=\sum_{k=0}^{n}(-1)^{k}\left(\begin{array}{l}n \\ k\end{array}\right) \frac{\tau^{k}}{k !}, n \geq 0$. The $I_{n}(\tau)$ are orthonormal over $(0, \infty)$ with weight $\exp (-\tau)$, i.๑.

$$
\int_{0}^{\infty} I_{m}(\tau) I_{n}(\tau) \exp (-\tau) d \tau=\delta_{m n}
$$

From (36) we obtain by a change of variables

$$
2 p \int_{0}^{\infty} I_{m}(2 \rho \tau) I_{n}(2 \rho \tau) \exp (-2 \rho \tau) d \tau=\sigma_{m n}
$$

so that the functions

$$
g_{n}(\tau)=\sqrt{2 \rho} I_{n-1}(2 \rho \tau) \exp (-\rho \tau), \quad n \geq 1,
$$

are orthonormal over $(0, \infty)$. Then, using (34) and (35), we express the $q_{n}(\tau)$ in terms of the $p_{n}(\tau)$, obtaining

$$
q_{n}(\tau)=\sqrt{2 / \rho} \sum_{k=0}^{n-1}(-1)^{k}\left(\begin{array}{c}
n-1 \\
k
\end{array}\right) 2^{k} p_{k+1}(\tau), \quad n \geq 1 .
$$

Eq. (38) is the explicit form of (28) in the case of Poisson sampling. Therefore, in this case $(30)$ becomes

$$
C(\tau)=\sum_{n=1}^{\infty} \beta_{n} g_{n}(\tau), \tau \geq 0,
$$


where $($ see $(29))$

(40) $\beta_{n}=\sqrt{2 / 0} \sum_{k=0}^{n-1}(-1)^{k}\left(\begin{array}{c}n-1 \\ k\end{array}\right) 2^{k} c_{h}(k+1), \quad n \geq 1$.

Egs. (38), (39) and (40) give $c(\tau)$ in terms of the correlation sequence $c_{h}(n)$. The analogous expression for the power spectrum $F(\omega)$ is (see (31) and (32))

$$
F(\omega)=\frac{1}{2 \pi} \sum_{n=1}^{\infty} \beta_{n}\left\{\Psi_{n}(\omega)+\Psi_{n}(-\omega)\right\} \quad,
$$

where the $\beta_{n}$ are given by $(40)$, and

$$
\begin{aligned}
\Psi_{n}(\omega) & =\sqrt{2 / \rho} \sum_{k=0}^{n-1}(-2)^{k}\left(\begin{array}{c}
n-1 \\
k
\end{array}\right) \phi^{k+1}(\omega) \\
& =\sqrt{2 / \rho} \sum_{k=0}^{n-1}(-2)^{k}\left(\begin{array}{c}
n-1 \\
k
\end{array}\right)\left(\frac{\rho}{\rho-i \omega}\right)^{k+1} \\
& =-\sqrt{20} \frac{(i \omega+\rho)^{n-1}}{(i \omega-0)^{n}}, \quad n \geq 1 .
\end{aligned}
$$

Next consider alternate Poisson sampling, where we sample only at every other point generated by a Poisson process. In this case, $p(\tau)$ is the function $p_{2}(\tau)$ of $(34)$, with characteristic function

$$
\phi(s)=\frac{\rho^{2}}{(\rho-i s)^{2}}
$$

Again, it is easy to see that this function takes no value more than once on the real axis, so that alternate Poisson sampling is also 
a]ias-free. icwever, remarkably enough, if we sample at every thiro time generated by a Foisscr process, aliasing creeps in. In. this case, $p(\tau)$ is the runction $\mathrm{p}_{3}(\tau)$ of $(3 / 4)$, with characteristic function

$$
\phi(s)=\frac{p^{3}}{(p-i s)^{3}}
$$

Since this function takes the same value at the points $s_{1}=p(2 \sqrt{3}+i)$ and $s_{2}=\rho(-2 \sqrt{3}+i)$, Therrem 2 guarantees the existence of aliases is this case.

Let $P$ be the class of probability densities in $I^{2}$ scr which

$$
\begin{aligned}
& p(\tau)=0, \\
& \int_{0}^{\infty} \tau p(\tau) \mathrm{d} \tau<\infty
\end{aligned}
$$

(corresponding to a non-zero rate of sampling), and whose Fourier itransforms take no value more than once on the real axis (and hence are schlicht in the closed upper half-plane). Each function of $\gamma$ characterizes an alias-free method of additive random sampling. There are various ways of finding members of $\varnothing$. For example, taking the real and imaginary parts of the condition

$$
\int_{0}^{\infty} p(\tau) \exp \left(i \omega_{1} \tau\right) d \tau=\int_{0}^{\infty} p(\tau) \exp \left(i \omega_{2} \tau\right) d \tau,
$$

we obtain 
(4I) $\quad \int_{0}^{\infty} p(\tau) \cos \omega_{1} \tau d \tau=\int_{0}^{\infty} p(\tau) \cos \omega_{2} \tau d \tau$

and

(42) $\quad \int_{0}^{\infty} p(\tau) \sin \omega_{1} \tau d \tau=\int_{0}^{\infty} p(\tau) \sin \omega_{2} \tau d \tau$.

If the sine transform is positive for $\omega>C$ and if the cosine transform is strictly decreasing, then, because of the different parities of the cosine and sine transforms, (4I) and (1.2) cannot both hold for $\omega_{1} \neq \omega_{2}$. Moreover, if $p(\tau)$ is strictly decreasing, it follows from

$$
\int_{0}^{\infty} p(\tau) \sin \omega \tau d \tau=\int_{0}^{\pi / \omega}\left[p(\tau)-p\left(\tau+\frac{\pi}{\omega}\right)+p\left(\tau+\frac{2 \pi}{\omega}\right)-\ldots\right] \sin \omega \tau d \tau
$$

that its sine transform is positive for $\omega>0$. Thus, the class $P_{0}$ of strictly decreasing $p(\tau)$ with strictly decreasing cosine transforms is a subclass of $P$. Functicns in $P_{0}$ can be found by inspecting tables of Fourier transforms. For example, $\rho \exp (-\rho \tau),(2 \rho / \pi) \exp \left(-\rho^{2} \tau^{2} / \pi\right)$ and $(2 \mathrm{k} \rho / \pi) \operatorname{sech}(k \rho \tau)$ are all in $P_{0}$; here, as usual, $\rho$ is the average sampling rate, and $k$ is the constant

$$
\frac{4}{\pi} \sum_{n=0}^{\infty} \frac{(-1)^{n}}{(2 n+1)^{2}} \cong 1.17
$$

Let $p(n ; \tau), n=1,2, \ldots$, be a family of probability densities in $P_{0}$, with

$$
\int_{0}^{\infty} \tau p(n ; \tau) d \tau=h_{n}
$$


Then it is easily seen that any function of the form

$$
p(\tau)=\sum_{n=1}^{\infty} a_{n} p(n ; \tau), \quad 0 \leq a_{n} \leq 1, \sum_{n=1}^{\infty} a_{n}=1
$$

is also in $\gamma_{0}$, provided that

$$
\int_{0}^{\infty} \tau_{p}(\tau) d \tau=\sum_{n=1}^{\infty} a_{n} h_{n}<\infty
$$

:ore generally, let $p(\alpha ; \tau), a \geq 0$, be a family of functions in $\gamma_{0}$, indexed by the continuous parameter $a$, with

$$
\int_{0}^{\infty} \tau p(\alpha ; \tau) d \tau=h(a) .
$$

Then any function of the form

$$
p(\tau)=\int_{0}^{\infty} p(a ; \tau) d \underline{d}(a)
$$

where $\Phi(a)$ is a probability distribution function, is also in $\gamma_{0}$, provided that

$$
\int_{0}^{\infty} \tau p(\tau) d \tau=\int_{0}^{\infty} h(\alpha) d \Phi(a)<\infty .
$$

From the foregoing, it is clear that alias-free sampling methods exist in abundance.

We conclude by noting that the rectangular distribution with probability density

$$
\begin{aligned}
& p(\tau)=\frac{1}{2 h}, \quad 0 \leq \tau \leq 2 h, \\
& p(\tau)=0, \tau<0, \tau>2 h,
\end{aligned}
$$


and characteristic function

$$
w=\not(s)=\frac{\exp (2 i h s)-1}{2 i h s}
$$

is not alias-free. To see this, we construct the image $\Omega$ in the w-plane of the first quadrant of the s-plane under the mapping (W4). $\Omega$ is shown schematically ir tine figure; it has infinitely many disjoint components separated from one another by the spiral curve (which passes repeatedly through the origin), and the outermost component is bouncied by the interval $(0,1)$, the image of the positive imaginary axis. Now consider two points $\mathrm{w}_{1}$ and $\mathrm{w}_{2}$ which, like those indicated, lie in different components of $\Omega$. These points correspond to two points $s_{1}$ and $s_{2}$ of the half-plane Ims $>0$, and the straight line segment joining $s_{1}$ and $s_{2}$ lies entirely in Ims $>0$. Moreover, since the image of this segment must intersect the spiral at a point $w_{3}$, there must be a point on the segment, $s_{3}$ say, at which $\phi(s)$ takes the same value $w_{3}$ as it does at some real $\omega_{0}>0$. Then, since $w=\phi(s)$ is analytic at $s_{3}$ and therefore takes all values sufficiently close to $w_{3}=\varnothing\left(s_{3}\right)$ in a neighborhood of $s_{3}$ (see $[7], p .184$ ), and since $\not \partial(s)$ is continuous at $\omega_{0}$, we can find some value near $w_{3}$ which is taken twice in the open upper half-plane. Hence, by Theorem 2, the "rectangular sampling scheme" with distribution (43) is not alias-free. 


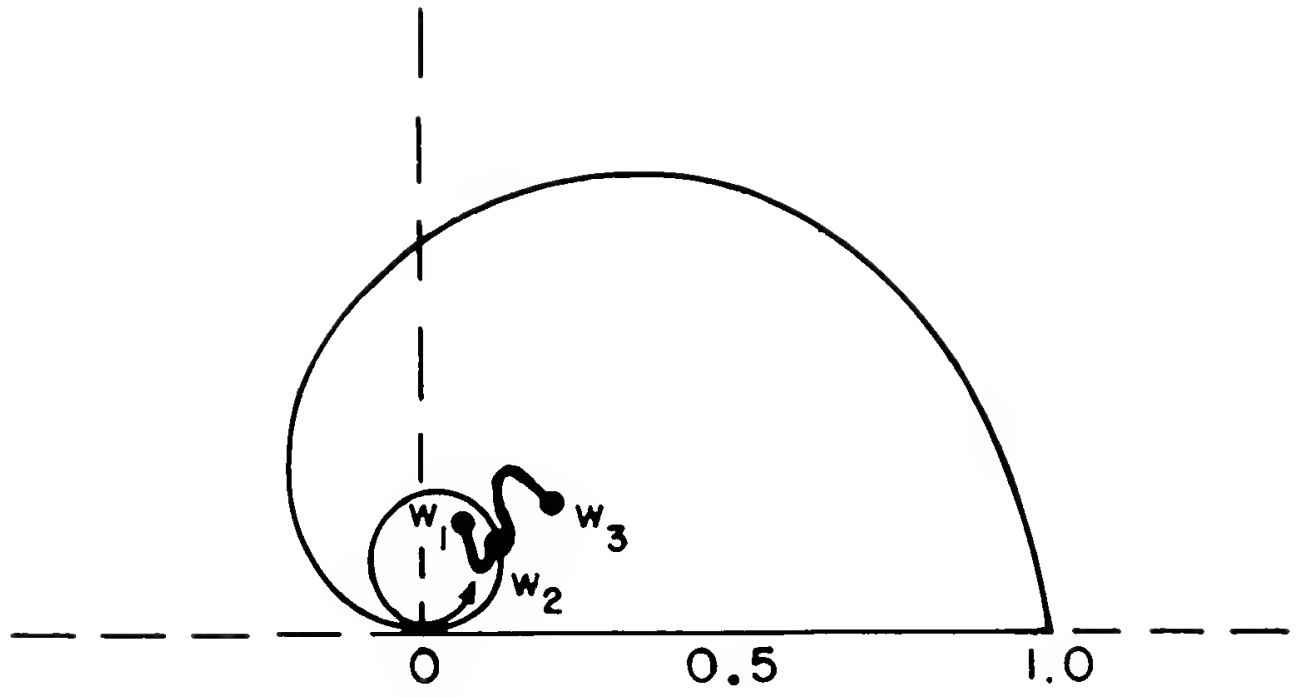

Image in the w-plane of the first

quadrant of the s-plane under the mapping (44) with $h=1$ (schematic). 
[I] Blackman, R.P. and Tukey, J. W.

[2] Meruyama, G.

[3] Grenander, U. and Rosenblatt, M.

[4] Wiener, $N$.

[5] Akhiezer, N. I.

[6] Titchmarsh, I. C.

[7] Bieberbach, L.

[8] Walsh, J. L.

[9] Szegö, G.

[10] Shapiro, H.S.
- The measurement of power spectra from the point of view of communications engineering; Bell System Tech. J., 37, $185-282$ Jan., $485-569$ Mar. (1958). Feprinted in book form by Dover Publications, New York (19,59).

- The harmonic analysis of stetionary stochastic processes; :iomoirs of the Fac. Sci., Kyusyu Univ., Series A, Vol. 4, No. 2, 45, 106, December (1949).

- Statistical Analysis of Staticnary Time Series, John Wiley, New York (19,57).

- The Fourier Integral and Certain of its Applications, Cambridge Univ. Press (1933). Reprinted by Dover Publications, New York.

- Theory of Approximation, translated by C. J. Hyman, Ungar Publishing Co., New York (1956).

- The Theory of Functions, second ed., Oxford Univ. Press (1939).

- Lehrbuch der Funktionentheorie, Vol. I, B. G. Teubner, Leipzig (1934). Reprinted by Chelsea, New York (1945).

- Interpolation and Approximation by Rational Functions in the Complex Domain; American Math. Soc., New York (1935).

- Crthogonal Polynomials; American Math. Soc., New York (1939).

- Generators of the Banach algebra $\mathrm{I}^{1}(0, \infty)$, to appear in Comm. Pure and Appl. Math. 

(ONE copy unless otherwise noted)

\section{Commander}

Alr Research and Development Command Andrews A1r Force Bage

Weshington 25, D. C.

Attn: Major E. Wright, RDTCC

D1rector of Resident Training 3380th Technicel Training Group Keesler A1r Forca Base, Mississippi Attin OA-3011 Courge

\section{Director}

Air Onfrersity Library

Maxwell Alr Force Base, Alabama

\section{Commander}

A1r Force Miesile Test Center

Patrick Air Force Besa, Floride

Attn: MTE - for clasgifled documents

Attni MO-4II, Technical Library - for unclessifled documents

Tacticel A1r Group

Directorate of Rasearch and Developmant $\mathrm{DCS} / \mathrm{D}$

Headquarters, USAF

Washington, D. C.

Attn: Major R. L. Stell

Director, Conmunications and Electronics Fq. D. S. Air Force

Washingt on $25, \mathrm{D} . \mathrm{C}$.

Atti AFOAC S/E

\section{Commander}

Wright Alr Davelopment Center

Wright-Petterson Air Force Bese, Ohio

Attni WCLRS-6, Mr. Portune

Wright Alr Development Center

Wright-Patterson Air Force Base, Ohio

Flight Research Laboratory

Research Division

Attn: WCRRh

\section{Commender}

Wright Air Development Center

Wright-Patterson Air Force Base, on10

Atta: N. Draganjac, wCLNo-4

\section{Commander}

Wright Air Development Center

Wright-Pattergon Air Force Base, Ohio

Attni Mr. Paul Springer. WCLRE-5

Commender

Ar Tachnical Intelligence Center

Wright-Patterson Air Force Base, Ohio

Attn: $A \pi C I N-4 B 1 a$

Commander

Rome A1r Development Centar

Griffias Alr Force Base, New York

Attn: RCSSTL-1

Commender

Rome Air Development Center

Griff1ss Air Force Base, New Tork

Attn: Mr. Donald Daken, RCUE

Commander

Rome A1r Development Center (ARDC)

Oriffios Air Force Bage, New York

Attn: Dr. John S. Burgass, RCE

\section{Commender}

A1r Force Missilo Development Center

Folloman A1r Force Base, New Mexico

Attn: HDOIL, Technical Library

Director

I. S. Army Ordnance

Balligtic Resaarch Laboratories

Aberdeen Proving Ground, Maryland

Attn: Belliotic Measurenents Laborator

Balliatic Research Laboratorleo

Aberdeen Proving Ground, Maryland

Attn: Technical Information Branch
Director

Evans Signal Eaboretory

Belmar, New Jareey

Attn: Mr. O. C. Woodvard

v. S. Amtay Signal Enginaering Labs. Evans Signal Laboretory

Belmar, New Jersey

Attn: Technical Document Center

Masaachusetts Inst1tute of Technology Signal Corps Lialson officer

Cambridge 39, Mass.

Attn: A. D. Bedros1an, Room 26-131

Commanding General, SIGFM/EL-PC v. S. AImy Signal Englneering Labs.

Fort Monmouth, New Jersey

Attn: Dr. Rorst H. Kedesdy Deputy Chief, Chem-Physics Pranch

\section{Commender}

Army Rocket and Gulded Miesile Agency

Redstone Arsenal, Alabams

Attn: Technical Library, ORDXR-OTL

Commanding General

U. S. Amy Signal Enginaering Labs.

Fort Mormouth, Naw Jersey

Attn: SIGFM/EL-AT

Department of the Army

Office of the Chlef Signal officer

Wrahington 25, D. C.

Attn: SIGRD-?

Office of Chief Signal officer

Engineering and Technical Division Washington 25, D. C.

Attn: SIGNET -5

Gided Miss1le Fuza Library

Dlamond Ordnance Fuze Lahoratorias

Washington 25, D. C.

Attn: R. D. Hatcher, Chief Microwave Devolopmant Section

(10)Armed Services Technical Informetion Agency

Arlington Hall Stotion

Arlington 12, V1rgin1a

(2) Library

Boulder Laboratoriee

National Bureau of Stenderds

Boulder, Colorado

Nationel Bureau of Standarda

Department of Cominerce

Washingt on 25, D. C.

Attn: Mr. A. G. MeNish

National Bureau of Standards

Department of Commerca

Washington 25, D. C.

Attn: Gustave Shapiro, Chief

Engineering Electronics Section

Electricity and Electronics Div.

(2) Office of Technical Services

Department of Commerce

Weshington 25, D. C.

Attn: Technical Reports Section (Unclassified only)

D1rector

National Security Agency

Washington 25, D. C.

Attn: $R / D$ (331)

(2) Ho. A1r Force Cambridga Research Center Laurence G. Henscom Field

Bedford, Mass.

Attn: CROTLR-2 - P. Condon

(5) Hq. A1r Force Cambridga Research Center Laurance G. Henscom Field

Bedford, Mass.

Attn: CROTLS - J. Armatrong
(5) Ha. Air Force Cambridge Research Center Laurence O. Hanscom Field Bedford, Mess.

Attn: CRRO

Director, Aronics D1vision (AV)

Bureau of Aeronautics

Department of the Nevy

Washington 25, D. C.

Chiaf, Bureau of Ships

Department of the Navy

washington 25, D. C.

Attn: Mr. E. Johnston, Code 833E

Connand ar

0. S. Naval A1r Missila Tegt Canter

Point Mugu, Celifornie

Attn: Code 366

v. S. Naval Ordnance Laboratory

White Oak

Silver Spring 19, Maryland

Attn: The Library

Commander

U. S. Naval Ordnance Test Station

China lake, Californio

Attn: Code 753

Lubrarian

U. S. Naval Poetgreduate School

Montarey, California

Air Force Development Field Representetive Naval Research Laboratory

Washlngton 25, D. C.

Attn: Code 1072

Director

D. S. Naval Regearch Laboratory

Wash1ngton 25, D. C.

Attn: Code 2027

Dr. J. I. Bohnert, Code 5210

U. S. Naval Research Leboratory

Washington 25, D. C. (Unclaseified only)

Classifled to he sent to:

Director

U. S. Naval Regearch Laboratory

Attn: Code 5200

Weshington 25, D. C.

Commanding officer and Director

D. S. Navy Underwater Sound Lahoratory

Fort Trumbul1, New London, Connecticut

Chiaf of Naval Research

Department of the Navy

keshington $25, \mathrm{D}$. C.

Attn: Code 42 ?

Commanding of ficer and Director

D. S. Navy Electronica Laboratory (Library)

San Diego 52, California

Chlef, Bureau of Ordnance

Department of the Navy

Washington $25, \mathrm{D} . \mathrm{C}$.

Attn: Code $\mathrm{Ad} 3$

Chief, Buraau of Ordnance

Department of the Navy

Surface Guided Missile Branch

Wash1ngton 25, D. C

Attn: Code ReSl-e

Chiaf, Bureau of Ordnance

Department of the Navy

Washington 25, D. C.

Attn: Fire Control Branch (ReSh)

Department of the Navy

Bureau of Aaronautics

Tachnical Data Diviaion, Code 4106

Wesh1ngton 25, D. C.

Chief, Bureau of Ships

Department of the Navy

washington $25, \mathrm{D}$. C.

Attn: Code 817 B 
Commandine officer

U. S. Naval A1r Development Center Johnsville, Pennsyl vania

Attn: NADC I1hrary

Comanander

V. S. Naval Air Test Conter

Patuxent River, Maryland

Attn: ET-315, Antenna Branch

Director

Naval Ordnanca Laboratory

Corona, Calffornta

Commanding of 1 icar

U. S. Naval Ordnance Lahoratory

Corona, California

Attn: Mr. W. Horenstein, Division 72

Airborme Instrumento Lahoratory, Inc. 160 old Country Road

Nineola, Naw York

Attn: Dr. E. G. Fubin1, Director Rasarch and Enginearing Division

Aircom, Inc.

354 Main Streat

Winthrop, Mass.

American Nachine and Foundry Company

Electronics Division

1085 Commonwealth Avenue

Boston 15, Mass.

Attn: Mrs. Rita Moravcsik, Librarian

Andrew Alford, Consulting Engineers 299 Atlantic Averus

Boston 10, Maoo.

Avion Division

ACF Industries, Inc.

800 No. Pitt Stragt

Alexandria, Virginia

Attn: Library

Battalle Memorial Institute

$505 \mathrm{KIng}$ Avenua

Attn: Wayne E. Rife, Project Leader

Elactrical Engineering Division

Columbua 1, Oh10

Ball Aircraft Corporation

Post orfice Box Ons

Buffalc 5, Naw York

Attn: Eunice P. Hazelton, librarian

Ball Telephona Laboratories, Inc.

Whippany Laboratory

Whippany, New Jersey

Attn: Technical Information Library

\section{Pacific Division}

Bendix Aviation Corporation

11 too Sherman Way

North Hollywood, California

Engineering Lihrary

Attr: Peggie Robinson, Librarian

Bendix Radio Division

Bendix Aviation Corp.

E. Joppa Road

Towson L, Maryland

Attn: Dr. D. M. Allison, Jr.

D1ractor Englneering and Rosaarch

Bosing Alrplane Company

Pilotless Aircraft Division

P.C. Box 370 ?

Seattle 24 , Washington

Attn: R.R. Barhar, Library Supervisor

Boeing Alrplane Company

Wichit Division Englneering Library

Wichita 1, Kansas

Attn: Kennath C. Knight, Librarian

Boeling Alrplane Company

Seattle Division

Sattle 1\%, Waohireton

Attn: E.T. Allen, Library Supervioor

BJorksten Rasearch Labs, Inc.

P. 0. Box 265

Madison, Wiscongin

Attn: Mrs. Fern B. Korsgard
Convalr, A Division of General Dynamics Corp.

Fort Worth, Texas

Attn: K.G. Brown, Diviaion Research Librarian

Convalr, A Division of General Dynemica Corp.

San Diego 12, California

Attn: Mrs. Dora B. Burke, Engineering Lbrarian

Cornell Aeronautical Laboratory, Inc. W 55 Genagea Streat

Buffalo 21, New York

Attn: Librarian

Dalmo Victor Company

A Division of Textron, Inc.

1515 Industrial Way

Belmont, California

Attn: Mary Ellen Addems, Technical Librarian

Dorne and Margolin, Inc.

29 New York Avenue

Westbury, Long Island, N. I.

Douglas Aircraft Company, Inc.

P.O. Box 200

Long Beach 1, California

Attn: Enginearing Library (C-250)

Douglas Alrcraft Co., Inc.

827 Lapham Straet

El Sagundo, Californis

Attn: Engineering Library

Douglae Aircraft Company, Inc.

3000 Ocean Park Boulevard

Sant a Monica, California

Attn: P.T. Cline

Eq. Sec. Reference Filao, Eq. Eng. A250

Douglas Aircraft Company, Inc. 2nno North Memorial Drive

Tulsa, Oklahoma

Attn: Engineering Library, D-250

Elactronicg Communication, Inc.

1830 York Road

Timonium, Maryland

Emeraon and Cuming, Inc.

869 Washington Straet

Canton, Mass.

Attn: Mr. W. Cuming

Emarson Elactric $\mathrm{Yfg}$. Co.

8100 West Florissant Avenue

St. Louis 21, Missour1

Att $n$ : Mr. E.R. Breolin, Librarian

Syl vanta Elec. Prod. Inc.

Electronic Dafenee Laboratory

P. C. Box 205 - (Uncl)

Mountain View, California

Attn: Library

Fairchild Alrcraft Division

Falrchild Eng. and Alrplane Corp.

Hagerstow, Maryland

Attn: Ltbrary

Farnsworth Electronics Company

3700 East Pontiac Street

Fort Wayne 1, Indiana

Attn: Technical Library

Federal Telecommunication Labs.

500 Washingt on Avenue

Nutley 10, Naw Jersey

Attn: Technical Library

The Gabrial Elsctrontcs

Division of the Gabriel Company

135 Creacant Road

Needham Helghts 94, Mass.

Attn: Mr. Steven Galagan
General Electric Advanced Electrontes Center Cornoll Univeraity

Ithaca, New York

Attn: J. B. Travis

Ganeral Electric Company

Electronics Park

Syracuse, New York

Attn: Documents Library, B. Fletcher Eullding 3-143A

General Praciaion Laboratory, Inc.

63 Bedford Road

Pleasant ville, New York

Attn: Mrs. Mary G. Harbst, Librarian

Goodvear Alrcraft Corp.

1210 Masallion Road

Akron 15, Oh10

Attn: Ifbrary D/120 Plant A

Grangar Associates

Electronic Systems

966 Comnercial Straet

Palo Alto, California

Attn: John V. N. Granger, President

Grumman A1rcraft Enginearing Corporation Bothpage, Long Island, N. $T$.

Attr: Mrs. A. M. Gray, Librarian Englneering Library, Plant No. 5

The Hallicrafters Company

4401 West $5 \mathrm{th}$ Avenue

Ch1cago 24. Illinols

Attn: LaVerne LaGiola, Librarian

Hoffman Laboratoriea, Inc.

3761 South H1ll Street

Los Angelea?, Californta

Attn: Engineering Library

Hughes Alrcraft Company

Antenna Department

$M 1$ crowave Laborator

Bullding 12, Room 2617

Culver C1ty, California

Attn: M. D. Adcock

Hughea Aircraft Company

Floranca and Teale Straets

Culver City, California

Attn: Dr. L.C. Van Atta, Assoclate Director Research Labs.

Hycon Eastern, Inc.

75 Cambridge Parkway

Cambridgo, Masa.

Attn: Mrs. Lols Seulowt Technical Librarian

International Business Machines Corp. Military Products Diviaion

5 on Madison A venue

Naw York 33, New York

Attn: Mr. C.F. McElwain, General Manager

International Busineas Machinas Corp.

Military Froducts Divigion

wego, Naw York

Attn: Mr. D. I. Marr, Lthrarian Department 459

International Resiatance Company

401 N. Brosd Street

Philadelphia 8, Pa.

Attn: Rasearch Library

Jankky and Bailay, Inc.

1339 Wisconsin Avenue, N. W.

Washington ?, D. C.

Attn: Mr. Delmer C. Port

Dr. Hanry Jasik, Consulting Enginear

298 Shames Drive

Bruah Hollow Indugtrial Park

Westbury, New York

Elactromgnatic Rasearch Cornoration

711 14th Street, N. W.

Washington 5 , D. C. 
Lockheed Alrcraft Corporation 2555 N. Follywood Way

California Divlaion Engineering Library Department 72-75, Plant A-1, Bldg. 63-1 Burbank, California

Attn: N. C. Harnols

The Martin Compary

P. 0. Box 179

Denver 1, Colorado

Attn: Mr. Jack McCormick

The Glenn L. Martin Company

Baltimore 3, Maryland

Attn: Engt nearing Library

Antanna Deaign Group

Marvland Electrontc Manufacturing Corp.

5009 Colvert Road

College Park, Maryland

Attri Mr. H. Warren Cooper

Mathematical Reviewe

190 Hope Street

Providence 6, Rhode Island

The W. L. Maxson Corporation

460 West 34 th Street

Naw York, N. $\mathrm{Y}$.

Attn: M1so Dorothy Clark

McDonnell Alreraft Corporation

Lambart Sasnt-Louls Munic1pal Airport

Box 516, St. Louls 3, Missouri

Attn: R. D. Detrich, Engineering Library

McMillan Laboratory, Inc.

Erownvilla Avenua

Ipswich, Massachusetts

Attn: Security Officer, Document Room

Melpar, Inc.

3000 Arlington Boulevard

Falls Church, Virginia

Attn: Engineering Technical Library

Microwave Development Laboratory

90 Broad Straet

Babson Park 57, Maseachusetta

Attn: N. Tucker, General Manager

M1crowave Radiation Company Inc.

19223 South Hamilton Straet

Gardena, Californda

Attn: Mr. Morris J. Ehrlich, President

Chance Vought Aircraft, Ino.

9314 West Jefferson Street

Dallas, Texas

Attn: Mr. H. S. White, Librarian

Northrop A1rcraft, Inc.

Hawthorne, California

Attn: Mr. E. A. Freitas, Library Dept 3145 1001 E. Broadway

Remington Rand Univ. - Divistion of Sperry

1900 West Allogheny Avenue Rand Corporation

Philadalphia 29, Pennsylvanis

Attn: Mr. John F. McCarthy

$R$ and $D$ Salea and Contracts

North American A viation, Inc.

1221/s Lakewood Boulavard

Downay, California

Attn: Englneering Library 495-125

North American Aviation, Inc.

Los Angelee International Alrport

Los Angeles 45, California

Attn: Engineering Technical File

Page Communications Engineers, Inc. 710 Fourteanth Street, Northwast

Washington 5 , D. C.

Attn: Librarian

Philco Corporation Research Division Branch L1brary

4700 Wlosachickon Avenue

Philadelphia Wh, Pa.

Attn: Mrs. Dorothy S. Collins
Pickard and Burns, Inc.

$240 \mathrm{HIghland}$ Averue

Needham 94, Mass.

Attn: Dr. J. T. DeBettencourt

Polytechntc Research and Development Company, Inc.

202 Tillarg Street

Brook lyn 1, New York

Attn: Tachnical LAbrary

Radiation Engineering Laboratory

Main Street

Maynard, Mass.

Attn: Dr. John Ruze

Radiation, Inc.

P. O. Drawer 3 ?

Malbourne, Florida

Attn: Technical Library, Mr. M.L. Cox

Radio Corp. of America

RCA Isboratories

Rocky Point, New York

Attn: P. S. Cartar, Lab. Library

RCA Laboratorias

David Sarnoff Rasearch Centar

Princeton, New Jersey

Attn: Miss Fern Cloak, Librarian Research Library

Radio Corporation of America

Defense Electrontc Projucts

Building 10, Floor?

Camden 2, New Jersey

Attnı Mr. Harold J. Schrader Staff Eng ineer, Organization of Chlef Technical Adminiotrator

(2) The Ramo-Wooldridge Corporation

P.C. Box 45453 Airoort Station

Los Angeles 45 , California

Attn: Margaret $C$. Whitnah, Chlef Librarian

Hoovar Microwa ve Co.

9592 Baltimore Avenue

College Park, Marvland

Director, USAF Project RAND

Viat Air Force Lialson office

The Rand Corporation

1700 Main Street

Santa Monica, California

Rantec Corporation

Calabasae, California

Attn: Grace Keener, Office Manager

Raytheon Manufacturing Company

Misatle Systems Diviaion

Bedford, Mass.

Attn: Mr. Irving Goldsteln

Raytheon Manufacturing Company

Wayland Laboratory, State Road

Wayland, Mass.

fttn: Mr. Robert Borts

Paytheon Manufacturing Comcany

wayland Laboratory

Wayland, Mass.

Attn: Miss Alice G. Anderson, Librarian

Republ1c A Nation Corporation

Farmingdala, Long Island, N. Y.

Attn: Engtneerine Library

Thru: A1r Force Plant Representat1ve Republic Aviation Corp. Farmingdale, Long Island, N.Y.

Rheem Manufacturing Company

9236 Esst Hall Road

Downey, California

Attn: J. C. Joerger

Trans-Tech, Inc.

P. 0. Box 31,6

Frederick, Maryland
Ityan Aeronautical Company

Indbergh Field

San Diago 12, Californte

Attn: Library - unclassified

Sage Laboratorias

159 L1nden Streat

Wollesley 81 , Mase.

Sanders Agsoctatas

95 Canal Street

Naahua, New Hampshire

Attn: N. R. Wild, Library

Sandia Corporation, Sandia Base

P.0. Sox 5800, Albuquerque, New Mexico

Attn: Classified Document Division

Sperry Gyroocope Company

Graat Neck, Long Island, New York

Attn: Florence W. Turnbull, Engr. Librarian

Stanford Research Institute

Menlo Park, California

Attnt Library, Engingering Division

Sylvania Electric Products, Inc.

ino Firat A venue

Waltham 5h, Nass.

Attn: Charles A. Thornh1ll, Report Lfbrarian Walthan Lahoratories Library

Systems Iaboratories Corporation

14.952 Ventura Boulevard

Sherman Daks, Californta

Attn: Donald L. Margerum

TRG, Ine.

17 Unton Square Wast

New York 3, N. Y.

Attn: M. L. Henderson, Litrarian

A. S. Thomas, Inc.

161 Devonshire Street

Boston 10, Mass.

Attn: A. S. Thomas, President

Bell Telephone Iaboratorles

Murray Hill

New Jersay

Chu Associates

P. 0. Box 38 ?

Whitcomb Avenue

Littleton, Mass.

Mcrowa ve Associates, Inc.

Burington, Masa.

Raytheon Manufacturing Company

Missile Division

Hartwell Poad

Bedford, Mass.

Radio Corporation of America

Aviation Systems Laboratory

225 Crescent Streat

Waltham, Maas.

Lockheed Aircraft Corporation

Missile Systems Division Research Library

Box 504, Sunnyrale, Calffornta

Attn: Miss Eva Lou Robertson, Chlef Librarian

The Rand Corporation

$1700 \mathrm{Ma}$ in Straet

Santa Monica, California

Attn: DT. W. C. Hoffman

Commander

AF Office of Sclentific Research

A1r Research and Development Command

Ilsth Street and Constitution Avenue

Washington, D. C.

Attn: Mr. Ntting, SRY

Westinghouse Electric Corp.

Elactronica Diviston

Friendahtp Int' I Alrport Box 71,6

Baltimore 3, Maryland

Attn: Engineering Library 
Wheeler Laboratories, Inc.

122 Cutter M111 Road

Great Neck, New York

Attn: Mr. Horold A. Wheeler

Zenith Plastica Co.

Box 91

Gardena, California

Attn: Mr. S. S. Olsesky

Library Geophysical Institute

of the Univergity of Alagks

Colloge

Alssk

Untrersity of Calfornta

Barkelay 4, California

Attn: Dr. Samuel Silver, Prof. Engineering Science Division of Elec. Eng. Electronles Research Lab.

Iniversity of California

Electronics Research Lab.

332 Cory $\mathrm{Hall}$

Berikeley 4 , California

Attn: J.R. Whinnery

Californis Institute of Technology

Jet Propulaion Laboratory

4800 Oak Grove Driva

Pasadena, California

Attn: Mr. I. E. Newlan

California Institute of Technology

1201 E. Calfforni a Strest

Pasadana, Californis

Attn: Dr. C. Papas

Carnagis Institate of Tachnology, Schenley Park

Pittsburgh 13, Pennsylvanis

Attn: Prof. A. E. Heins

Cornell University

School of Electrical Engineering

Ithaca, New York

Attnt Prof. G. C. Dalman

Inlversity of Florida

Department of Electrical Engineering

Gaineaville, Florida

Attn: Prof. M. H. Latour, Library

Iihrary

Georg1a Inst1tute of Technolagy

Enginesring Experiment Station

Atlanta, Georgia

Att $n$ : Mrs. J.H. Crosland, Librarian

Harverd Univerafty

Technical Reports Collection

Gordon Mcksy Library, 303A Pierce Hall

Oxford Street, Cambridge 3R, Mass.

Attn: Mrs. E.L. Hurschmidt, Librarian

Harvard College Observatory

60 Gardsn Street

Cambridge 39, Mass.

Attn: Dr. Fred L. Whipple

Iniverelty of Illinols

Documents Division Library

Urbana, Mlinots

University of Illinols

College of Engineering

Urbana, Illinots

Attn: Dr. P. E. Moyes, Department of Electrical Engineertng

The Johns Hopking University

Homewood Campus

Department of Physics

Baltimore 1B, Maryland

Attn: Dr. Donald E. Kerr

Sandia Corporation

Attn: Organization $1 / 23$

Sandia Bsse

Albuquarque, New Mexico
Applied Physics Laboratory

The Johra Hopkins Univeraity

8621 Georgia A venue

Silver Spring, Maryland

Attn: Mr. Georgo L. Selolatad

Masachusette Institute of Tachnology Research Laborstory of Electronice Room 20B-221

Cambridge 39, Massachusette

Attn: John H. Hewtt

Massachusetts Institats of Technology

Lincoln Laboratory

P. 0. Box 73

Lexington 73, Mass.

Attn: Document Room A-229

University of Michigan

Electronic Defense Group

Engl nesring Research Institute

Ann Arbor, Michigan

Attn: J. A. Boyd, Supervilaor

Oniversity of Michigan

Enginearing Research Institute

Radiation Laboratory

Attn: Prof. K. M. Slegal

912 N. Main St.

Ann Arbor, Michigan

Oniversity of Michigan

Englneering Research Inst1tute

Willou Run Laborgtorles

W110 Run Airport

Yosilant1, Michigan

Attn: Librarian

University of Minnesote

Minnespolis 14, Minnesoto

Attn: Mr. Robert H. Stumn, Library

Northweatern Univergit

M1crowave Laboratories

Evanston, Mlinois

Attn: R. E. Bears

Ohfo State Univereity Resaarch Found.

Oh10 State University

Columbus 10, Ohio

Attn: Dr. T.E. Tice

Dept. of Elsc. Engineering

The Untrersity of Oklshoma

Research Institate

Norraan, Oklahoma

Attn: Prof. C. I. Farrar, Chairman Electricsl Engineoring

Polytechnic Institute of Brooklyn

Microwave Research Institute

55 Johnson Straet

Brooklyn, New York

Attn: Dr. Arthur A. Ol1ner

Polytechnic Institute of Brooklyn

Merowave Research Ingt1tuts

55 Johnson Street

Brooklyn, New York

Attn: Mr. A. E. Laemel

Syracuse University Research Institute Collendala Campus

Syracusa 10, New York

Attn: Dr. C. S. Grove, Jr. Difector of Engineering Research

The Unfiversity of Tsxas

Elec. Eng Ineerling Research Laboratory

P. 0. Box 8026, Univeraity Station

Austin 12, Texas

Attn: Mr. John P. Gerhardt Assistant Drractor

The Univergity of Texas

Defense Resarch Laboratory

Austin, Texas

Attn: Claude W. Horton, Phrgics Library

University of Toronto

Department of Electrical Enginearing

Toronto, Cansds

Attns Prof. G. Sincleir
Lowell Technological Institute

Resesrch Foundation

P. 0. Box 709, Lowell, Mass.

Attn: Dr. Charles R. Mingins

University of Washington

Department of Electrical Englnasing

Seattle 5, Waghingtion

Attn: G. Held, Associate Professor

Stanford Uni veraity

Stanford, Californla

Attn: Dr. Chodorow Microwave Laboratory

Physical Science Laboratory Veu Maxdco College of Agriculture and Mechanic Arts

St ate College, New Medico

Attn: Mr. H. W. Haas

Brow University

Depertment of Electrical Engineerling

Providencs, Phode Island

Attn: Dr. C. M. Angulo

Case Institute of Technology

Cleveland, Ohio

Attn: Pror. S. Seeley

Columbia University

Department of Electrical Englneering

Morningside Helghts

Naw York, N. Y.

Attn: Dr. Schlosinger

McGill University

Nontreal, Canada

Attn: Prof. O. A. Woonton

D1rector, The Eaton Elactronics Research Lab.

Purdue Dnivergity

Department of Electrical Enginearing

Laf ayette, Indiane

Attn: Dr. Schultz

The Pennsylvania State Univeraity Department of Electrical Engineering Unlversity Park, Pennsylvania

University of Pennsvivania

Institute of Cooperative Research

3 hoo WrI nut Street

Ph1ladelphia, Pennayl rania

Attn: Deot. of Electrical Engineering

University of Tennessee

Ferrts Hell

W. Cumberland A verue

Knoxv1119 16, Tannessee

University of Wisconsin

Department of Electrical Englneering

Madison, Wisconsin

Attn: Dr. Schaibe

University of Seattla

Department of Elactrical Englneering

Seatt Ie, Washington

Attn: Dr. D. K. Reynolds

Wryne Unt veraity

Detrolt, Michigan

Attn: Prof. A. F. Stevenson

Electronics Rasearch Laboratory

IIIInols Institute of Technology

3300 So. Federal Street

Chicago 16, I1linois

Attn: Dr. Laster C. Paach Research Engineer

Advisory Group on Electronic Parts Room 103

Moore School Bu1lding

200 South 33rd Streat

Philadelphia 4 , Pennsyl venta 
Jonosphero Rosesrch Laboratory

Pennsyl vania State Colloge

State College, Pannsylvania

ATT. Profesaor A. H. Wamick, Director

Institute of Mathematical Sciences

25 Waverly Place

New York 3, New York

ATTN: Librarian

Electronica Division

Rand Corporation

$1700 \mathrm{Main}$ St.reet

Santa Monica, California

ATTN: Dr. Robert Kalaba

National Bureau of Standaris

Washington, D. C.

ATTN: Dr. W. K. Saunders

Applied Mathematics and Statistics Lab. Stanford Uni versity

Stanford, alifornia

ATTN: Dr. Albert H. Bowker

Departmert of Physics and Astr nomy

Michizan State College

East Lansing, Michizan

ATTN: Dr. A. Leitner

University of Tennessee

Knoxville, Tennessee

ATTN: Dr. Fre! A. Ficken

Lebazon Jalley College

Annville, Pennsylvanis

ATTN: Professor B.H. Blssinger

Gencral A tomio

P. 0 . Box 608

San Diego 12, California

Department of Physics

Amherst College

Anherst, Mass.

ATTN: Dr. Armold Arons

California Institute of Technology

$1201 \mathrm{E}$. California Street

Pasadens, Californta

ATTN: Dr. A. Erdalyt

Mathematics Depertment

Stanford lind versity

Stanford, California

ATTN: Dr. Harold Levino

University of Minnesots

Minneapolis I', Minnegota

ATTN: Professor Paul C. Rosenbloon

Department of Mathematics

Stanford Dniversity

Stanford, Califortia

ATTN: Professor Bernard Epstain

Applied Physics Laboratory

The Johns Hopking University

8621 Georgia Avenue

Silver Spring. Marrland

ATTN: Dr. B. S. Gourary

(2) Exchange and Gift Divilon

The Library of Congras

dashington 25, D. C.

Electrical Engineering Department Massachusetts Institute of Technolngy Cambridge 39, Mass.

ATSN: Dr. L. J. Chu

Nuclear Degelopment Associates, Inc. 5 New Streat

White Pla1ng, New York

ATTN: Library

California Institute of Technology

Electrical Engineering

Pasadena, California

ATT: Dr. Zohrab A. Kaprielian
Dr. Rodman Doll

$311 \mathrm{~W}$. Cross Street

Ypsilanti, Michigan

Califomia Inst. of Technology

Pagadena, Californis

ATT: Mr. Calvin Wilcox

(3) Mr. Robert Brockhurst

Woods Hole Oceanographic Institute

Woods Hola, Mass.

National Buraau of Standards

Boulier, Colorado

ATTN: Dr. R. Gallet

Dr. Solomon L. Schwabal

3689 Irou1s Roas

Palo Alto, Pallfornia

University of Minnesote

The University of Library

Minneapolis 14 , Minnesota

ATTN: Exchange Division

Department of Mathematics

University of Califomis

Berkeley, Califomia

ATTV: Profes三or Bernard Fríledman

Lincoln Laboratory

Masyachusetts Institute of Technology

P. D. Box 73

Laxington 73, Massachuset ts

ATT: Dr. Shou Chin Wang, Room C-351

Melpar, Inc.

3000 Arlingt on Boulevard

Falls Church, Virginia

ATTN: Mr. K. S. Kelleher, Section Head

Hq. Air Force Cambridge Research Center Laureuce G. Hanscom Fiald

Bedford, Mass.

ATT: Mr. Francis J. Zucker, CRRD

Hq. Air Force Cambridge Researoh Center Laurence G. Hanscon Field

Bedford, Masa.

ATTN: Dr. PhIlip Newinan, CRRK

Mr. N. C. Gerson

Trapelo Road

South Lincoln, Mass.

Dr. Richard B. Barrar

Svatems Development Corp.

2400 Colorado A venire

Santa Monica, Califomia

Colunbia University Hudson Laboratories P. O. Box 239

145 Palisade Street, Dobbs Ferry, N. Y.

ATTN: Dr. N. W. Johnson

Institute of Fluid Dynamies

and Applied Mathematics

University of Maryland

College Park, Maryland

ATTN: Dr. Elliott Montroll

Depsrtment of Electrical Engineering Washington University

Saint Louis 5, Mo.

ATTN: Professor J. Van Bladel

Departinent of the Nary

Orfice of Naval Rasearch Branch orfice

1030 E. Groen Streat.

Pasadena 1, California

Brande1s "niversity

Waltham, Mass.

ATTN: Library

General Electric Company

M1ctowava Laboratory

Electronica Division

Stanford Industrial Park

Palo Alto, California

ATTH: Lihrary
Smyth Research Associates

3555 Aero Court

San Diego 3, California

ATTN: Dr. John B. Smyth

Electrical Engineering

California Institute of Technology

Pasadena, California

ATTV: Dr Georgas G. Weill

Naval Rasaarch Laboratory

Washingt on 25, D. C.

ATTN: Menry d. Passerint, Code 5278A

Dr. George Kear

5 Culver Court

Orinda, California

Brooklyn Polytechnis

85 L1vingston Street

Brooklyn, New York

ATN, Dr. Nathan Marcuritz

Department of Elactrical Engineering Brooklyn Polytechnic

85 Livingston Street

Brooklym, New York

ATTN: Dr. Jerry Shmoys

Department of Mathematica

University of New Mexico

Albuquerque, New Mexico

ATTN: Dr. I. Kolodner

Mathenatics Depertment

Polytechnic Institute of Brooklyn

Johnson and Jay Street

Brooklym, New York

ATTN: Dr. Harry Hochatadt

Ballistics Research Laboratory

Aberdeen Proving frounds

Aberdeen, Marvland

ATTN: Dr. Pullen Reats

Dr. Lester Kraus

4935 Whitehaven Way

San Diego, California

University of Minnesota

Institute of Technology

Minneapolis, Minnosota

At $n$ : Dean Athelston Spilhaus

Ohio State Univeraity

Columbus, Ohio

Attn: Prof. C. T. Ta1

Departant of Electrical Eng.

Naval Research Laboratories

Washington 25, D. C.

Attn: W. S. Ament, Code 5271

Naval Research Leboratory

Washington 25 , D. C.

Attn: Dr. Leslie G. McCracken, Jr. Coda $3933 \mathrm{~A}$

Office of Naval Regaarch

Department of the vavy

Attn: Geophysics Branch, Code 416

Washington $25, \mathrm{D} . \mathrm{C}$.

orfice of Chief Signal officer

Signel Plans and Operations Division

Attn: SIGOL-2, Room 20

Com. Liaison Br., Radio Prop. Sect.

The Pentagon, Washington 25, D. C.

Defence Research Member

Canadian Joint Staff

2001 Connecticut Street

Washington, D. C.

Central Radio Prop. Lab.

National Buraau of Standards

Attn: Technical Reports Library

Boulder, Colorado

U. S. Weather Bureau

U. S. Department of Commerce

Waghinction $25, D$. C.

Attn: Dr. Harry Wexler 
Federal Communications Comission

bash1nt ton 25, D. C.

Attn: Mrs. Barbars C. Grimeg, ILbrartan

Upper Atmosphere Research Section Central Qad10 Propagation Laboratory National Buresu of Standaris

Bouldar, Colorado

Argonns vational Lahoratory

F.ก. Pox 299

Lemont, Illinols

Attn: Dr. Hoylande D. Yourg

Bell Telephone Labs.

Murray H111, New Jersey

Attn: Dr. S. 0. Rice, $33-203$

Carnegle Institute of Washington

Dept. of Terrestrial Magnetism

52l] Broad Branch Road, N. W.

Washington 15 , D. C.

Attn: Library

$225 \mathrm{~N}$. Avenue, N. W.

Attn: Dr. James E. Boyd

Atlanta, Georgla

Indversity of Maryland

College Park, Maryland

Attn: Dr. A. Weinstein

Institute of Fluld Dynamics

Massachusetts Institute of Technologv

Incoln Lahoratory

P. ก. Box 73

Lexdinton 73, Nassachusetts

Attn: Frof. Radford, DIvision 3 Head

Wllow Run Research Center

"niversity of Mlchigan

Willow Run Airport

Ypsilant1, Mich1Ean

Attn: Dr. C. L. Dolph

School of Engineering

Jew York Ind versity

Thi versitw Heights

New York, New York

Shell Fellowsip Cormittee of the Shell Companies Foundation, Inc.

50 West 5oth Street

New York 20, N. F.

Attn: Mr. J. R. Jansa日n

Esso Research and Enginearling Co.

P. ?. Box 51

Linden, New Jersey

Attn: Mr. C. L. Brown, Manazer

Enion Carbide and Carbon Corp.

30 E. 42 nd Street

New York 17, Naw York

Attn: Mr. L. E. Erlantson

\section{Convalr}

San Diego 12, Californis

Attn: Mr. Marvin Stern

Bell Telephone Labs., Inc.

1,63 West Street

New York 13, Y. Y.

Attrn: Dr. Mervin J. Kelly

Enginearing Library

University of Californd a

405 H1lgard A venue
Ceorgia Tech Research Institute

Los Angelos 24, Californis

Conva1r, A D1v. of Ceneral Iynamics Corp.

Fort Worth 1, Texas

Attn: F. '. Lavia, Chlof Englneer

Convalr. A Div. of General Dynamics Corn.

Pomonh, California

Attn: C. I. Perrine

Ass't D1v. Manager, Eng1n.

Shell Development Comany

Exploration and Production Res. DIv.

3737 Bellaire Bouleverd

Houston 25, Texas

Attn: Miss Aphrodite Mamculides

RCA Laboratories

Frincetcn, New Jersey

Attn: Dr. Cherles Foly

Stanford Research Ingt1tute

S. Pasadera, Caljforia

Attn: Dr. J. Prandstatten

Wayno State University

"resge-Hooker Sclence Itbrary

5250 Second Boulerard

Detrolt 2, Michigan

ARPA

1 Bond Street

Westbury, L. I., New York

Attn: Dr. Noman Spector

Vartan Assoclates

tIl Hansen Way

Palo Alto, Califorria

Attn: Mrs. Perry Conway Technical Librarian

Case Institute of Technology

Department of Electrical Enein.

I'niversity Circle

Cleveland 6 , Ohio

Attn: Prof. Robert Plonsey

Dr. Mire S. WOHE, CRRKP

Alr Force Cambridge Research Center

Laurence $G$. Hanscom Field

Fedford, Massachusetts

Fhysics Section

AVCO-PAD Diviaton

20 South Union Street

Lawrence, Noss.

Attn: Dr. Ernest Batuer

Advarced Development Saction

Wastern Davelopment Labs.

Philco Corp.

3875 Fabian Way

Falo Alto, Californda

Attn: Dr. Albert R. Glddis

Department of Aeronautical Engineering

Undversity of Nichigan

Ann Arbor, Michigan

Attn: Prof. Mahinder ibaroi

Gordor McRay Laboratory

Harvard University

Cambridge 39, Nass.

Attn: Dr. S. R. Seshadri

Commander

Alr Research and Develoment Command

Attn: RDTR

Andrews Air Force pase

washington $25, D, C$.

College of Engineering

Dept. of Electrica? Engineering

Indversity of Florida

Galnesvile, Florida

Daingerfield, Texs

Attn: J. E. Amold, Division Manager

Attn: Dr. Sullturn

Convalr, A Division of Cen

Attr: R. L. Bavlegs, Chief Englneer

Dr. V. H. Papadoponlos

Dept. of Engineering

Convalr, Diviston of General Dymamics Corp. Prown Undversity

San Diego 12, Califorala

Attn: F. J. Bossart, Chief Engineer-isio?A
Frovidence. R. I.
Mafor Vemon Lee Drwon

PSDD-OML (MO)

Rodstone Arsens]

Huntsullle, Alabama

Cruman Alrcarft Engineerine Corp.

South Cvater Pay Road

Rethpage, Lons, Island, v. Y.

Attr: Dr. Cherlos Mack

Af Office of Sclontific Research

Washington $25, D$. C.

Attn: Dr. Ker] Kanler

University of Californla

Radiation Laboratory

F. D. Rox ode

L1 vermore, Californda

Attn: Dr. Bernard A. Lipponan

Department of Electrical Engineerirg

Case institute of Technology

University Clrcle

$c l e v e l$ and $t$, onio

Attn: Professor Altert E. Collin

Antenna Laboratory

Air Force Cambrigge Research Caiter

Laurence C. Hanscom Field

Bedford, Massachusetts

Attn: Mr. Philip Blackstone

Lt. Mark J. Bersn, CRRD

A1r Force Camtridze Research Conter

Laurence G. Hanscom Fleld

Bedford, Nossachusetts

Pir. Rtchard Mack, CRRD

Air Force Cambridge Pesearch Center

Laurence G. Hanscom Field

Bedford Massachusetts

Svstem Develoment Corporation

2500 Colcrado A venue

Santa Monica, Californda

Atti: Library 



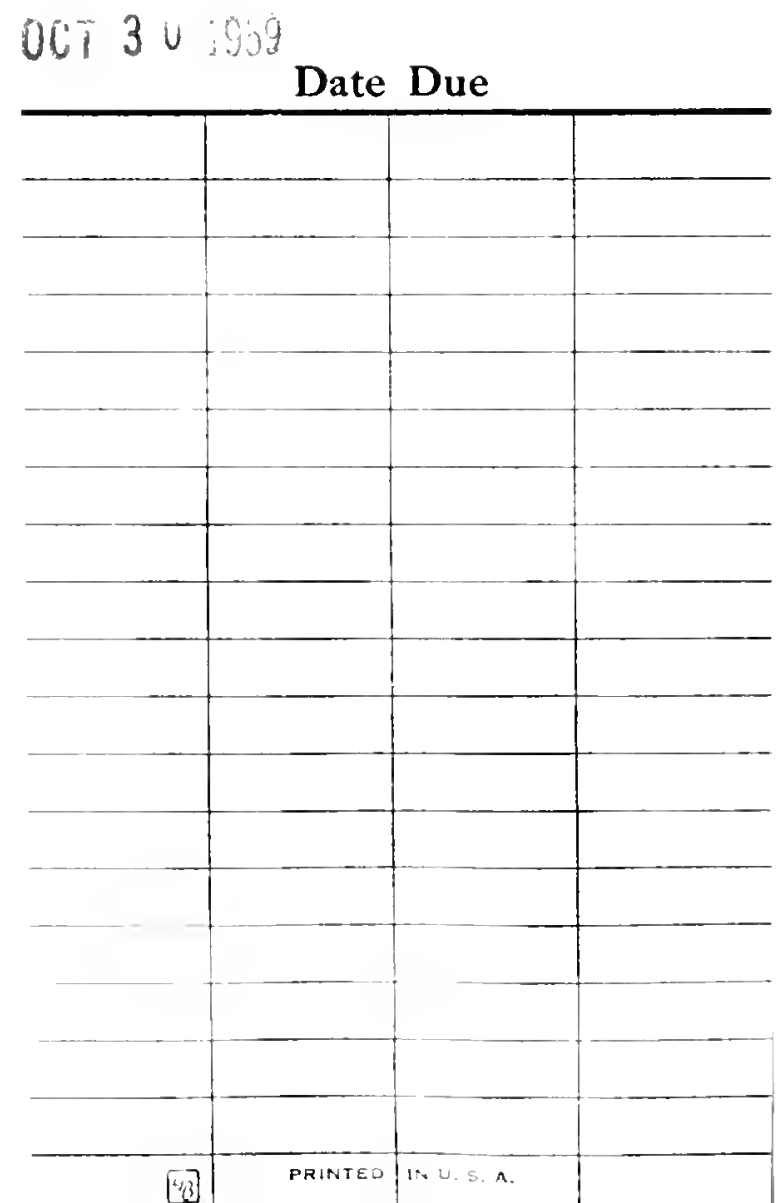




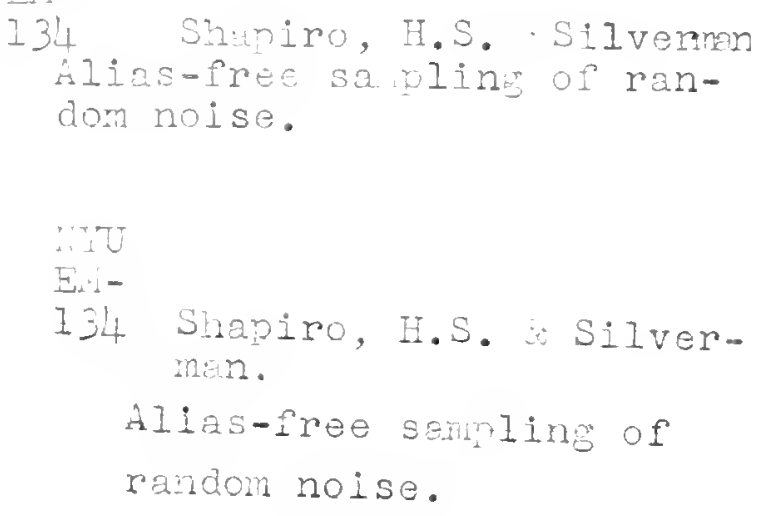

N. Y. U. Institute of

\section{Mathematical Sciences}

25 Waverly Place

New York 3, N. Y. 
